\title{
Criterios \\ El Real Colegio Seminario de San Telmo de Sevilla (desde 1700 hasta la década de los años setenta del siglo XVIII)
}

Delfín Rodriguez Ruiz

Catedrático de Historia del Arte. Universidad Complutense de Madrid

\section{Resumen}

En el siglo XVIII, con las intervenciones de los Figueroa, primero Leonardo y posteriormente sus hijos Matias y Ambrosio y su nieto Antonio, el Colegio Seminario de San Telmo incorpora modificaciones constructivas importantes, que marcan en buena medida el aspecto externo actual del edificio. El presente articulo trata de descubrir las claves de esta actividad constructiva especialmente entre 1700 y 1780, durante los reinados de Felipe V, Fernando VI y Carlos III. El edificio de San Telmo heredado de la época barroca deja ver paradójicamente la tradición formal y conceptual sevillana.

\section{Palabras clave}

\section{Real Colegio Seminario de San Telmo}

Sevilla

\section{$1700-1779$}

Historia

Patrimonio inmueble
La compleja historia constructiva del Colegio Seminario de San Telmo durante el siglo XVIII, y más concretamente entre 1700 y 1780, tuvo dos momentos decisivos, fundamentales en todos los sentidos, sin olvidar que en los primeros años de la centuria la actividad constructiva fue también importante. El primero de ellos coincide con los años veinte y treinta del siglo. Se trata de la época en la que el arquitecto Leonardo de Figueroa se hizo cargo de las obras y en la que, con él e inmediatamente después, también proyectaron y trabajaron algunos otros miembros de su saga familiar, como sus propios hijos, Matias y Ambrosio de Figueroa, especialmente el primero, como después se verá.

El segundo momento importante, desde el punto de vista proyectual, para la historia del edificio, durante el siglo XVIII, ocupa desde los años cincuenta a finales de los setenta, también vinculados a la tradición y modificaciones introducidas en el mismo por los Figueroa y que culminarian con el proyecto para terminar el Colegio Seminario presentado, en 1776 (según documentación del Archivo General de Simancas, Marina, Leg. 216), por Antonio de Figueroa, nieto e hijo, respectivamente, de Leonardo y Ambrosio de Figueroa. Se trata de una época, sin embargo, con un muy lento avance de las obras.

De estos datos documentales, a los que cabe añadir otros de carácter económico, conocidos y analizados desde la importante aportación de A. Herrera García (1958) a la más reciente de Elisa María Jiménez (2002), entre otros muchos historiadores que han estudiado durante los últimos años los aspectos económicos, históricos, pedagógicos y sociales del Colegio de San Telmo, pueden deducirse algunas cuestiones fundamentales para la comprensión y análisis del edificio y su historia constructiva.

En primer lugar, que esos dos periodos mencionados, en los que el protagonismo de la saga de los Figueroa no sólo está documentado, sino también evidenciado en los lenguajes mismos del edificio y en la resolución compositiva y tipológica del Colegio, coinciden con los de mayores ingresos económicos de la institución durante el Setecientos y también con los de mayor gasto en las obras del mismo, especialmente en el primer período mencionado. Es cierto que entre 1780 y 1808 los ingresos aumentaron, pero los gastos no fueron destinados en su mayor cuantía a las obras del edificio, ni muchísimo menos, ya que lo fueron, en ese período (1781-1808), a salarios, sustento cotidiano, vestuario, extraordinarios, pago de la renta a la Inquisición y atención a los nuevos porcionistas (alumnos de nuevo origen en esa época). En resumen, en esos años, a partir del llamado habitualmente "plano" de Francisco Pizarro, de 1781, y que es, en realidad, como es sabido, copia de otro de Antonio Camargo (el plano de Camargo copiado por Pizarro se conserva en la Universidad de Sevilla y es sobradamente conocido), los gastos en obras nuevas estuvieron en torno al $5 \%$ de los ingresos, siendo los de mantenimiento (reparaciones, obras de fontanería, etc.) del edificio similares (también el $5 \%)^{1}$. 


\section{$048-049$ Criterios}

El Real Colegio Seminario de San Telmo de Sevilla $(1700-1780)$

\section{PH51 - Diciembre 2004}

Es decir, que las etapas fundamentales en la construcción del Colegio corresponden, desde el punto de vista de los gastos realizados en las obras y, por tanto, en el avance del proyecto original de 1681, al primer período, entre 1681 y 1697, ya comentado, y al comprendido entre 1715 y $1739^{2}$, casi coincidente con la actividad de Leonardo de Figueroa y sus hijos, especialmente Matías. Curiosamente, y según los datos aportados por E. M. Jiménez, se invirtió más en la construcción del edificio (fundamentalmente en obras de cimentación, incluida las de la primitiva iglesia, según las cuentas de gastos, en Archivo Histórico de la Universidad de Sevilla, en adelante AHUS), entre 1698 y 1714, época que siempre se consideró como poco significativa desde el punto de vista del avance de las obras, también por coincidir con el cambio dinástico y la Guerra de Sucesión, que en la comprendida entre los años cuarenta y setenta del XVIII y también, aunque se haya podido pensar y afirmar lo contrario, que entre 1780 y 1800 , período que siempre se ha pensado como el que cierra definitivamente como inacabado, con la dirección de las obras por Lucas Cintora, el primitivo Colegio hasta que, en 1849 , es adquirido por los Duques de Montpensier para convertirlo en palacio y puesta su terminación en manos del arquitecto Balbino Marrón, cuya intervención sería fundamental, decisiva, para la imagen final del edificio, tanto por haber asumido en su proyecto la herencia de los Figueroa, como por haber entendido, frente a sus propias convicciones académicas y clasicistas ${ }^{3}$, que debía mantenerse en esa tradición, posiblemente por considerar que se trataba de una "arquitectura de la ciudad", en cuya configuración tuvo un papel primordial Leonardo de Figueroa y, tal vez, ayudado u orientado en esta idea por los propios Duques de Montpensier.

Resumiendo mucho los datos y el estudio de los mismos realizado por Elisa María Jiménez, es posible señalar que los gastos realizados en la construcción del edificio proyectado en 1681, dejando a un lado los relativos al mantenimiento del mismo y de los otros que procedian del "barrio" de San Telmo, de la Inquisición, se distribuyeron de la siguiente forma:

1. Entre 1681 y 1697: 1.604 .930 reales de vellón.

2. Entre 1698 y 1714: 973.572 reales de vellón.

3. Entre 1715 y 1739: 2.640.826 reales de vellón.

4. Entre 1740 y 1756: 73.069 reales de vellón.

5. Entre 1757 y 1776: 487.432 reales de vellón.

6. Entre 1777 y 1808: 880.866 reales de vellón. ${ }^{4}$

Estos datos coinciden, además, con los vaivenes de los ingresos, motivados por diferentes causas ajenas a la voluntad de los responsables del Colegio de San Telmo y a su previsto programa. Conviene hacer, sin embargo, una apreciación significativa: entre 1681 y 1776, los gastos en obras, sueldos de profesores, ministros, servidores y otros profesionales y manutención de los alumnos fueron prácticamente idénticos. Es decir, que, en ese largo y fundamental periodo de casi un siglo, la actividad del Colegio (manutención de alumnos y sueldos) era considerada tan importante, e incluso prioritaria, como la terminación de la construcción. Lo que resulta lógico y com-
${ }^{1}$ Vease, al respecto, E. M. Jiménez, El Real Colegio Seminario de San Telmo de Sevilla (16811808), pp. 41-69.

${ }^{2}$ Véase al respecto la obra de E. M. Jiménez. El Real Colegio de San Telmo de Sevilla..., op. cit., que recoge toda la bibliografía anterior y la documentación correspondiente.

${ }^{3}$ Según confirman sus informes de tasación del edificio en 1849, como arquitecto de los Mont pensier, y le reprocha, en reveladora polémica, el arquitecto tasador nombrado por la Administración, Francisco de Paula Alvarez (documentación del A.G.A. de Alcalá de Henares).

${ }^{4}$ E. M. Jiménez, El Real Colegio Seminario de San Telmo de Sevilla (1681-1808), Sevilla, 2002, pp. 57-69.

prensible si se entiende que la urgencia y función de la institución era la de formar pilotos y otros profesionales del arte de marear. El edificio se iba ajustando así, en su crecimiento, a las otras necesidades y funciones del Colegio. Es precisamente entre 1776 y 1808 , según los datos tabulados y analizados por diferentes historiadores $y$, fundamentalmente, por E. M. Jiménez, cuando el equilibrio se rompe, destinando casi todos los gastos a manutención y sueldos, quedando reducidos los relativos a obras a sólo un cinco por ciento del total y esto en un período de fuerte recuperación en los ingresos económicos. Esto podría explicar que las obras en ese período (aproximadamente entre 1777 y 1849) se redujeran casi exclusivamente a lo realizado por Cintora a partir de 1786 y ya mencionado y que el edificio permaneciese en ese estado hasta la compra del mismo por los Montpensier, poniéndolo en manos de Balbino Marrón (sus planos, conservados en Sanlúcar, así lo confirman).

Es decir, que mientras que en la primera mitad del siglo XVIII, coincidiendo con el reinado de Felipe $V$, el edificio avanzó con aportaciones muy notables, compositivas, tipológicas y de lenguaje, durante la segunda mitad, coincidiendo con los reinados de Fernando VI y Carlos III, la actividad constructiva, mucho menor y menos significativa en todos los sentidos, se redujo casi a un lánguido, pero a veces polémico, y lento laborar constructivo, aunque fue también la época en la que se puso un empeño nada desdeñable de diseño y conceptual con el fin de terminar el edificio, si bien es cierto que siempre entendidos ambos, proyecto y concepto, como una forma de continuar procedimientos disciplinares propios de la cultura barroca y de la tradición que del mismo edificio podían deducirse, como puede comprobarse en los diferentes proyectos presentados para concluirlo en las décadas de 1770 y 1780 y en los que tuvieron un papel protagonista profesionales de formación tan distinta como arquitectos, alarifes, carpinteros y profesores de artillería, matemáticas y dibujo, según cada cual, como Antonio de Figueroa (que presentó un proyecto en 1776, copiado por Francisco Pizarro y por el que fue premiado y elogiado, Pizarro que no Antonio de Figueroa, como consta en la documentación del Archivo General de Simancas, en adelante A.G.S.), o Antonio Camargo, carpintero, alarife y maestro de obras del colegio en esos años, cuyo proyecto, elaborado entre 1779 y 1780, para terminar el edificio, conocemos, aunque no en su totalidad, gracias a la copia que hizo Francisco Pizarro en 1781 (conservada en la Universidad de Sevilla), y el propio Pizarro, alumno del colegio, artillero y profesor de matemáticas y dibujo en el mismo, que presentó otro proyecto posteriormente, en 1786, y alternativo al de Camargo y que no se ha conservado, pero del que existe constancia documental (A.H.U.S.). No se puede olvidar, sin embargo, que ya desde el proyecto de 1776, de Antonio de Figueroa, Lucas Cintora informó de ese y de los sucesivos proyectos mencionados, hasta hacerse cargo de las obras en 1787 (la obra de Cintora en el Colegio puede seguirse en la documentación conservada en Simancas, Archivo de Indias y Archivo General de la Marina en El Viso del Marqués, entre otros archivos), siguiendo tanto la traza original de 1681 como las modificaciones de Leonardo y Matías de Fi- 
1. Ignacio Sala, Fábrica de Tabacos y Colegio de San Telmo, 1728. Archivo General de Simancas. MPD. 20/67

2. Sebastián van der Borcht, Fábrica de Tabacos y Colegio de San Telmo, 1764.
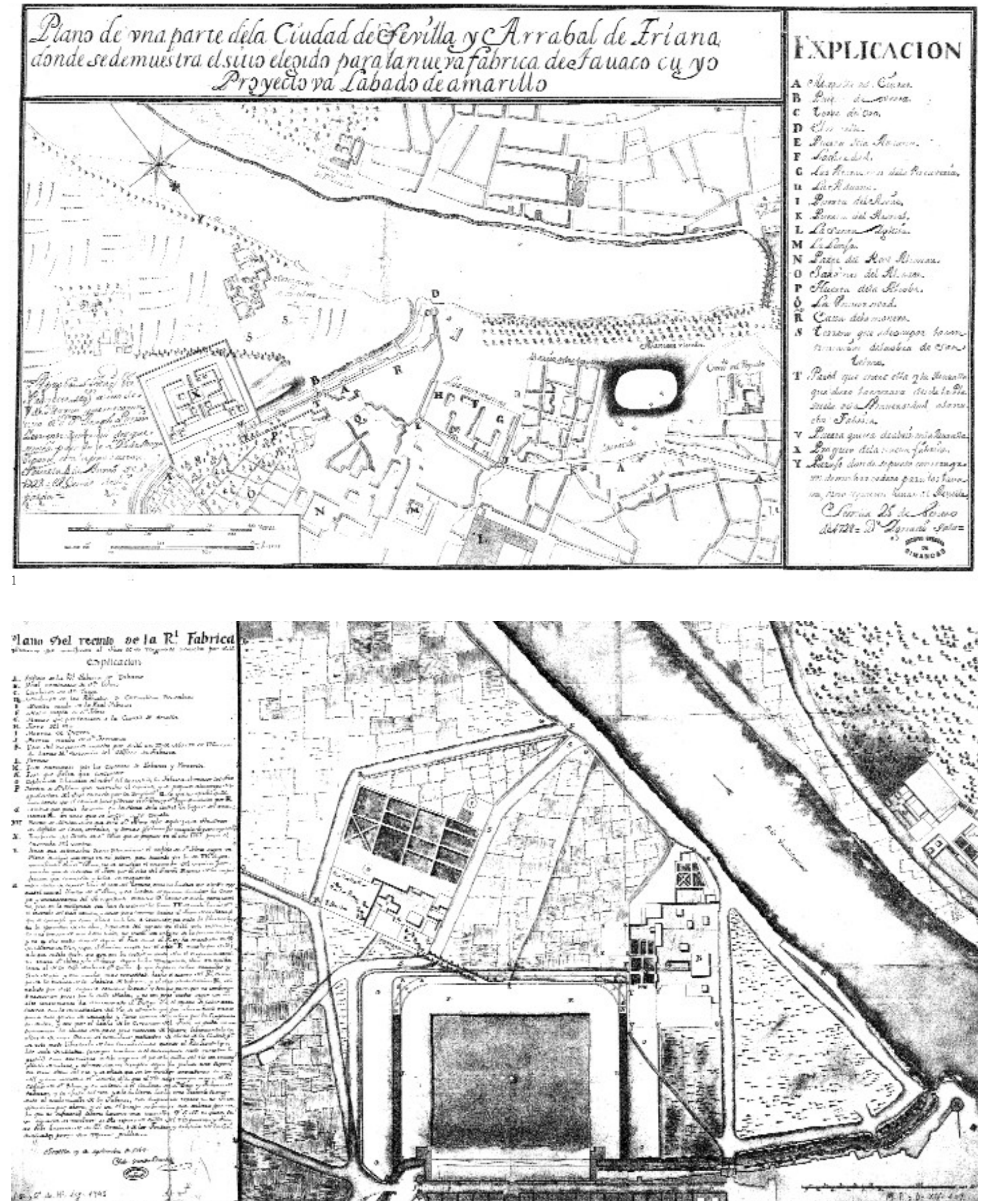


\section{$050-051$ \\ Criterios \\ El Real Colegio Seminario de San Telmo de Sevilla $(1700-1780)$ \\ PH51 - Diciembre 2004}

gueroa, que alteró en sus propuestas ornamentales con la intención de simplificarlas, de reducirlas, especialmente en el claustro principal y conociendo, además, los tres últimos proyectos mencionados de los cuales tuvo que informar por encargo expreso del Colegio de San Telmo.

No deja de ser sorprendente, por otra parte, que el Colegio de San Telmo encargara las obras a Lucas Cintora en esa época, precisamente la de mayor peso de Francisco Pizarro en el mismo, por entonces ya primer Catedrático de Matemáticas, habiendo sido no sólo alumno del Colegio, sino, además, antes de 1787 y después de 1773, maestro de artillería y dibujo y, sobre todo, aspirante a dirigir las obras del Seminario de San Telmo al menos desde 1776, cuando usurpó el proyecto de Antonio de Figueroa para la terminación del edificio y fue premiado por "su" plan (A.G.S., Marina, Leg. 215).

Es decir, y resumiendo estos prolijos datos documentales, que el Colegio Seminario de San Telmo fue, durante el siglo XVIII, un edificio que, partiendo de una traza de 1681, muy posiblemente de un maestro de obras como Antonio Rodriguez ${ }^{5}$, es una construcción atenta a tradiciones tipológicas, compositivas y de len-
3. Diego Bordick, Fábrica de Tabacos y Colegio de San Telmo, 1741. Archivo General de Simancas, MPD. 23/61 guaje tradicionales, e incluso propias de la ciudad de Sevilla, cuya definición formal y figurativa adquirió todo su significado proyectual y conceptual durante el siglo XVIII gracias a Leonardo de Figueroa y a sus inmediatos seguidores. La cultura académica, ilustrada, propia del siglo de las Luces, sólo alcanzó, por mano de Lucas Cintora, a concluir la escalera principal, en el lugar previsto por Leonardo de Figueroa y por el proyecto original, si atendemos al informe de Urbizu-Rodríguez, de 1699, ya comentado en esta "memoria histórica" (Doc. de Archivo General de Indias, en adelante A.G.I., y del Archivo de la Marina en El Viso del Marqués, Sección Colegios, Leg. 992) y a desnudar de ornamentos lo que quedaba por hacer en lo ya construido. Poca aportación, sin duda, en la Sevilla llustrada, pero que resume bien una actitud generalizada, la de simplificar y desornamentar los lenguajes de la arquitectura, en toda España en esa época, como es conocido. Por otra parte, es suficiente comparar el plano de Camargo, copiado por Pizarro en 1781, con los de Balbino Marrón de 1849 y 1850 (Arcivo de Sanlúcar), para comprobar que la obra avanzó poco en esos casi setenta años, aunque al principio de ese período las intenciones, planos y proyectos, conservados o no, pudieran hacer pensar lo contrario. En términos constructivos, casi todo se redujo a lo aportado por Lucas

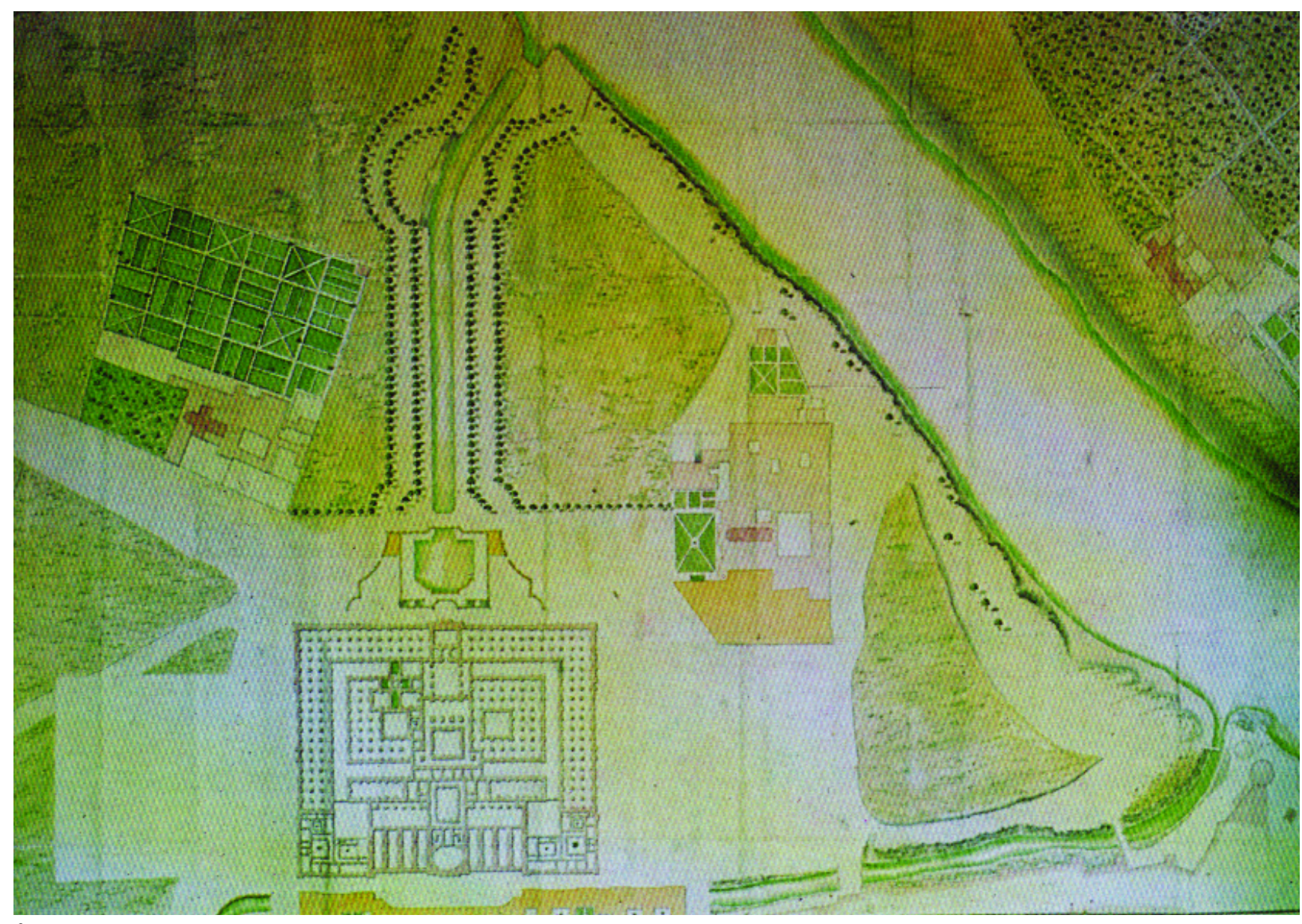


Con motivo de su fallecimiento en 1707, los libros de cuentas del Colegio, conservados en el A.H.U.S, dicen que "de Antonio Rodriguez maestro mayor que fue del dicho colegio que por aver muerto con suma pobressa y no dexar con que enterrarse determinamos hazerle esta limosna en atención a lo mucho que a sercido al dicho colegio y ser el que formo su planta y dio princio a la obra de su fabrica.". Las negritas son mías, pero la afirmación ya habia sido advertida anteriormente por otros historiadores.

${ }^{6}$ Véase, al respecto, M. C. Mena Garcia. Las propiedades del Colegio Seminario de San Telmo en el siglo XVIII. En AA. VV., Andalucia y América en el siglo XVIII. Actas de las III Jornadas de Andalucia y América, Sevilla, 1985, pp. 325-339.

Cintora en la escalera, claustro y zaguán. Luego, en realidad, el edificio quedó inacabado y sustancialmente definido por obra de Leonardo de Figueroa, continuada por sus hijos y nieto (Matías, Ambrosio y Antonio de Figueroa), hasta que lo dirigió y finalizó Balbino Marrón, ya en época de los Montpensier, siguiendo la obra como si de un miembro más de la familia de los Figueroa se tratase, aunque, como ya he señalado, en contra de su formación y convicciones.

Resumiendo mucho estos datos, y antes de pasar a analizarlos en sus consecuencias arquitectónicas más significativas, podría afirmarse, con carácter muy general y en relación al edificio de San Telmo que:

1. Hubo un primer proyecto para el barrio de Triana, del que se conserva el dibujo (planta) (AGI), que no se construyó.

2. Que, en el mismo año de 1681, el rey Carlos II aprobó un segundo proyecto, para el lugar de San Telmo, extramuros de la ciudad de Sevilla, en terrenos de la Inquisición, que fue por el que se guió la construcción del mismo durante los años finales del siglo XVII y XVIII, al menos en términos tipológicos, compositivos y volumétricos. Por la documentación y dibujos conservados (aunque indirectos estos últimos, como luego se verá), ese edificio tenía forma rectangular, con torres-miradores en las cuatro esquinas (a las que se hace mención en numerosos documentos), disponiendo un eje axial con la portada de la fachada principal, zaguán, patio e iglesia, dispuesta esta última, en el proyecto original, en posición longitudinal en la crujía Este del edificio.

3. Sobre este segundo y decisivo proyecto de 1681 pueden, además, hacerse algunas afirmaciones fundamentales:

3.1. Fue diseñado por arquitecto o arquitectos que trabajaban en Sevilla, muy posiblemente por el maestro A. Rodríguez, según in dicios documentales, algunos especialmente precisos.

3.2. El proyecto respondia a un programa de necesidades planteado en las sucesivas Cédulas Reales promulgadas al respecto, cuya recopilación es prolija, ya que los volúmenes con ese título son distintos en contenido en cada una de las colecciones conservadas (A.H.U.S, A.G.I., Biblioteca Real -Palacio Real de Madrid-, Museo Naval, Biblioteca Nacional, etc.). Del cotejo de todos ellos se desprende la elaboración de un programa de necesidades y funciones que el proyecto debía recoger, como así fue en líneas generales, sucesivamente modificadas en función de la propia actividad del Colegio, cada vez más compleja.

3.3. Que una copia de la planta del colegio de 1681, aprobada por Carlos II, estuvo colgada en la contaduría del mismo, en el cuarto del "arca de tres llaves", creado a finales del siglo XVII (1697-1698), durante todo el siglo XVIII (la observación se encuentra en diferentes menciones realizadas en documentos de A.G.I. y A.G.S.).
3.4. Que de ese plano se hicieron numerosas copias, algunas manejadas incluso por los ingenieros militares responsables de las obras de la Fábrica de Tabacos, como confirman distintos documentos y, entre otros, el plano levantado, en 1764, por S. Van der Borcht (A.G.S.) para hacer visible el conflicto planteado entre la Fábrica de Tabacos, su foso y camino en relación a los terrenos de San Telmo y en el que afirma que dibuja el plano de San Telmo "según un plano antiguo que tengo en mi poder...".

3.5. Que ese plano planteaba un edificio rectangular con torres en las esquinas y una sola fachada principal. A él se refieren también Ignacio Moreno y F. Tirado, en 1775 , con motivo de su plano levantado para el litigio con el Ayuntamiento a propósito del trazado de un camino arbolado entre la Fábrica de Tabacos y San Telmo (A.G.I).

3.6. Que el plano de 1681 se abrió paso entre las construcciones del llamado "barrio" de San Telmo ${ }^{6}$, usando de algunas de las mismas para iniciar sus actividades mientras se iba levantando la traza, muchas de las cuales quedaron vinculadas a su perimetro, aunque a diferente altura, hasta la época en que Balbino Marrón se hizo cargo de las obras para los Duques de Montpensier, a mediados del siglo XIX. Fue este arquitecto el que limpió de adherencias constructivas, viejas y nuevas, el bloque del edificio, dotándole además de otras tres fachadas no previstas en principio, siguiendo, en los lenguajes, la estela de los Figueroa.

4. El plano de 1681 obedecía a una tipología y a una idea de la arquitectura anclada en tradiciones de la arquitectura sevillana (hospicios, hospitales, conventos, etc.) y a procedimientos barrocos de composición que no fueron sustancialmente alterados durante el siglo XVIII e incluso continuados por Balbino Marrón en el siglo XIX, al menos en términos de lenguajes arquitectónicos, lo que convierte su actuación en particularmente significativa, como se analiza después en este informe histórico.

5. Que durante los años veinte del siglo XVIII, Leonardo de Figueroa hizo suyo el edificio, no sólo en los lenguajes, sino en su disposición tipológica y compositiva, convirtiéndolo en una arquitectura de la ciudad. Lección que no fue alterada durante el XVIII e incluso acentuada intencionadamente por Balbino Marrón, con la excepción de la limpieza de ornamentos en el claustro del patio principal por L. Cintora.

6. Que la intervención de Leonardo de Figueroa, con el cambio de eje de la iglesia y sus importantes consecuencias, dio origen a un plano "variado", según dicen los documentos, que debió estar en el origen del proyecto de terminación del edificio elaborado por su nieto Antonio de Figueroa en 1776.

7. Que entre ese año de 1776 y 1780 se sucedieron diferentes proyectos para la terminación del edificio que en nada alteraban su tradición barroca. 


\section{$052-053$ Criterios}

El Real Colegio Seminario de San Telmo de Sevilla $(1700-1780)$

\section{PH51 - Diciembre 2004}

8. Y que, a partir de 1787, Lucas Cintora sólo realizó la escalera en el lugar previsto por Figueroa, cerró finalmente las pandas del claustro y limpió de ornamentación el patio.

Este escueto resumen proporciona, sin embargo, algunas ideas fundamentales para la comprensión arquitectónica del Colegio Seminario de San Telmo, no sólo en el siglo XVIII, sino al menos hasta la obra de Balbino Marrón iniciada a partir de 1849.

Como ya se ha comprobado, hubo una traza general aprobada en septiembre de 1681 por Carlos II para construir el edificio. La traza pesó de manera muy significativa, al menos hasta mediados del siglo XIX, en la historia arquitectónica y constructiva del edificio, es decir, mientras dependió directamente de la Corona, aunque fuera de ministerios o Consejos distintos. Lo levantado hasta entonces, la historia misma del edificio, aún mantuvo su peso en la obra de terminación definitiva de Balbino Marrón para los Duques de Montpensier, nuevos propietarios del edificio, pero ya no por razones de obediencia a Reales Ordenes que garantizaban la corrección de lo construido con respecto a lo aprobado, en una concepción administrativa habitual en la arquitectura de promoción regia u oficial, sino por una elección consciente, intencionada, de definir una determinada filiación estilística y de gusto que vinculase la obra nueva y las nuevas funciones y usos del edificio, ahora palacio privado, a la tradición misma de la construcción y a su relación con la propia arquitectura de la ciudad, como confirman los planos, memorias e informes de mediados del siglo XIX (Archivo General de la Administración, en adelante A.G.A., de Alcalá de Henares y Archivo de Sanlúcar) y la propia obra realizada a partir de entonces.

La influencia de ese primer proyecto fue fundamental, al menos en su volumetría, tipología y atención a un programa muy preciso de usos y funciones, descritas en minuciosas y sucesivas Cédulas Reales, que se iban modificando casi cotidianamente en función de los avatares propios de la institución, tanto económicos, como docentes, de habitación, tanto de alumnos como de ministros, profesores o sirvientes, o de vida cotidiana (roperos, lavaderos, graneros, lugares comunes, enfermería, etc.). A él se remitían siempre las nuevas obras y el avance de la construcción. También fue usado en sucesivos litigios, como argumento decisivo, con el Ayuntamiento de la ciudad o con la propia obra de la Fábrica de Tabacos durante el siglo XVIII, para defender su traza, aún no terminada de construir, de ocupaciones intrusas.

La construcción del Colegio se atuvo rigurosamente a este plano durante finales del siglo XVII y hasta la intervención en las obras de Leonardo de Figueroa en 1721-1722. Es decir, que las obras tuvieron este lógico pie forzado, un proyecto aprobado por el Rey, que debía responder además a un programa muy preciso. El inicio de las obras por el lado sur del rectángulo no fue accidental ni casual, ya que esa era la parte destinada en el proyecto y en el programa, según las diferentes Reales Cédulas recopiladas y conservadas, a habitación (dormitorios) de los colegiales, aulas,
${ }^{7}$ C.E.A., "El Palacio de San Telmo, en Sevilla”, en Arquitectura, XI, núm. 119, 1929, pp. 83-94.

4. Portada principal del Colegio-Seminario de San Telmo (1724-1734). En SANCHO CORBACHO, A. Arquitectura Barroca Sevillana, Madrid: Consejo Superior de Investigaciones Científicas, 1984, lámina 34

5. Fachada posterior de la capilla del Colegio-Seminario de San Telmo (1724-1734). En SANCHO CORBACHO, A. Arquitectura Barroca Sevillana, Madrid: Consejo Superior de Investigaciones Científicas, 1984, lámina 44

refectorio, cocinas, enfermeria, ropero, etc. y primeras, y provisionales, viviendas de algunos ministros, profesores, sirvientes y capellán, estas últimas situadas en esta zona mientras se terminaba el edificio, utilizando incluso viejas construcciones del Ilamado "barrio de San Telmo", no sólo como viviendas, sino como lugares de servicio (tahonas, graneros, dormitorios provisionales de los alumnos, mientras se levantaba el Colegio).

El informe de Domingo de Urbizu y de Antonio Rodríguez, de 1699, confirma con precisión lo realizado hasta entonces y lo iniciado, con especial atención a la cimentación de la iglesia y elevación de algunas de sus partes, especialmente la cabecera, situada en una posición central y con claustro pegado a su costado occidental, según se desprende de la documentación, y habitual, por otra parte, en otros edificios de usos y funciones colectivos de Sevilla (conventos, centros asistenciales y obras pías), desde el siglo XVI. Pero el mencionado informe de Urbizu y Rodriguez, de 1699, también indicaba lo que quedaba por hacer, como ya ha sido puesto en evidencia en la primera parte de esta memoria histórica.

Es decir, y los documentos así lo confirman, además del plano de Antonio Camargo, copiado en 1781 por Francisco Pizarro, según él mismo se encarga de escribir en el propio dibujo, que el Colegio comenzó a levantarse por el lado sur, poniendo un especial hincapié en su clara definición programática y tipológica, destinando la crujía meridional a dormitorios, así como la oriental hasta encontrar con la iglesia y su cabecera. La crujía de la fachada principal, hasta la portada, destinada a aulas en el proyecto original, tuvo diferentes usos hasta que se levantó la iglesia ya en tiempos de Figueroa, incluyendo una capilla provisional (esta capilla provisional es descrita en los documentos, así como en el libro de Mateo Limón, Breve descripción del sumptuoso edificio de San Telmo..., 1738) y un espacio para colocar el navío, a escala real, que Carlos II regaló al Colegio para atender la formación de los futuros pilotos de la marina, intención primera de la institución y función original del edificio. Estas tres crujias (la principal, al oeste, hasta el hueco de la puerta de entrada, la sur y la este, hasta encontrar con la iglesia) y sus dos torres-miradores angulares casi dictan el resto del edificio. Su escala, dimensiones y usos, sabiendo que el espacio central estaba ocupado por la disposición de la iglesia, longitudinal al lado este, el claustro y la entrada, reclaman una composición simétrica, al menos en cuanto a volúmenes perimetrales, al otro lado, el norte, el más tardio en ser resuelto y terminado.

Un elemento fundamental del lado sur, junto con los dormitorios, como se evidencia en el plano de 1781, es el del refectorio, con acceso desde el claustro o patio principal. Es en torno a esos volúmenes y espacios, las tres crujías y el refectorio, en donde se organizan patios de luces con distintas funciones y para atender a tareas distintas, de servicios, docentes, de vivienda de profesores y sirvientes o de habitación de los alumnos. Se trata de una relación entre volúmenes construidos y patios que se evi- 


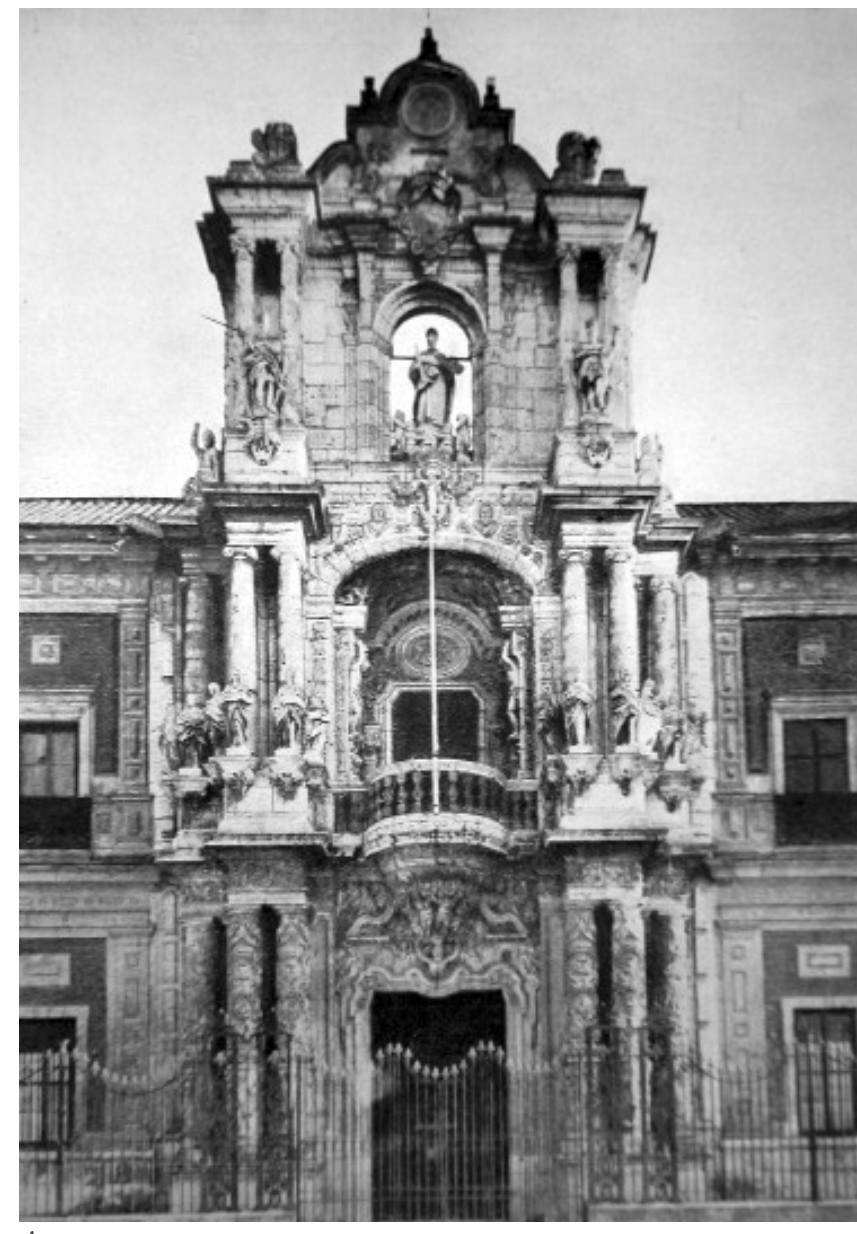

dencia también en los planos indirectos que representan el proceso del proyecto de San Telmo en los conservados relativos a la Fábrica de Tábacos y los distintos litigios seguidos por el Colegio durante el siglo XVIII (A.G.S.). Algunas fotografias de esos patios, publicadas en la revista Arquitectura ${ }^{7}$, en 1929, y luego destruidos por Basterra en agresión incomprensible, confirman que se trataba de patios y construcciones de menor escala que las crujías principales y que el refectorio (Lo confirman también los planos de Balbino Marrón conservados en Sanlúcar). Precisamente por el fallo de una columna en uno de esos patios comenzó la vinculación de Leonardo de Figueroa con el edificio en 1721 (A.H.U.S. y A.G.I.).

No se puede olvidar que, por ejemplo, los dormitorios, situados al sur y al este, recibían su luz y ventilación fundamentalmente de estos patios, ya que al exterior eran casi opacos, sólo horadados con algunas puertas de salida a espacios de descanso o servicios o de comunicación con viejos edificios, muchos de ellos pertenecientes al antiguo barrio de San Telmo, propiedad de la Inquisición, en cuyos terrenos se levantó el colegio (el plano de Camargo-Pizarro y los de Balbino Marrón, 1849-1850, así lo confirman).

De hecho, esta circunstancia nos habla de que, en el primitivo proyecto, sólo se pensó en una fachada principal con huecos de ventanas ordenados con regularidad, que sintomáticamente son una versión, como ya ha sido notado en diferentes ocasiones, de la articulación de las del edificio de La Lonja o Casa de Contratación de Juan de Herrera, en Sevilla. De hecho, Lucas Cintora, cuando se hace cargo de las obras a partir de 1787, Ilamó la atención (Archivo de la Marina, El Viso del Marqués) sobre esa falta de ventilación y luz de los dormitorios de los colegiales, lo que, indirectamente, confirma que en el proyecto original nunca se

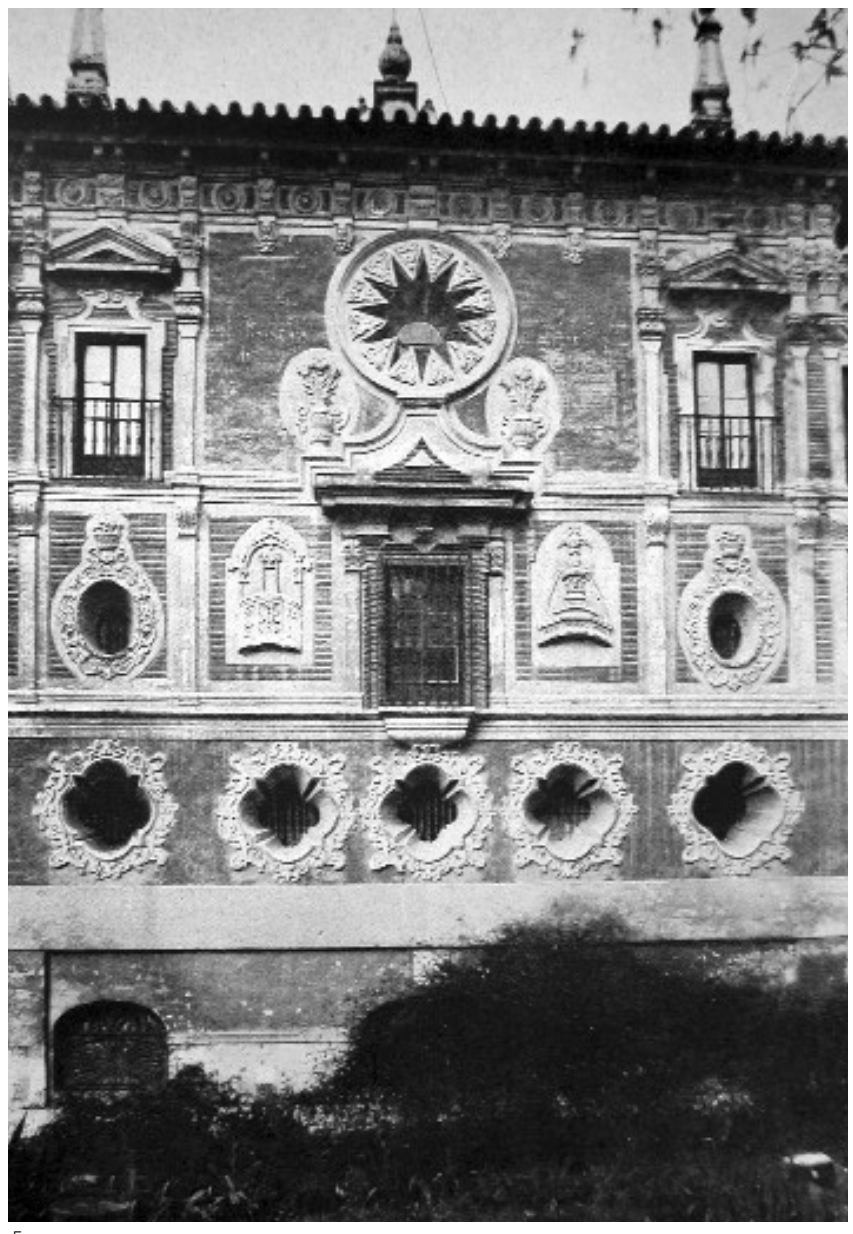

pensó en otras fachadas articuladas por ventanas que no fuera la principal, con la portada de Figueroa, si bien es cierto que Antonio Camargo pensó, en su proyecto de terminación del edificio, de 1779-1780, proporcionar al colegio una fachada con portada en su crujía norte, según los documentos conservados en A.H.U.S (Sevilla), A.H.N. -Archivo Histórico Nacional- (Madrid) y en A.G.S. (Simancas). Es decir, que Camargo, alarife y carpintero de formación empírica, tradicional y barroca, entendió que la ciudad, a causa de la nueva construcción de la Fábrica de Tabacos y sus consecuencias urbanísticas, reclamaba del edificio, por su lado norte, una fachada (la construcción de la Fábrica de Tabacos, las nuevas vías abiertas hacia el muelle del río, así parecían imponerlo). Estos datos confirman también, además de la evidencia escrita en el propio plano, que el llamado, por costumbre, "plano de Francisco Pizarro", de 1781, es copia del de Camargo, aunque posiblemente con alguna alteración, como por ejemplo el hecho de que no presente la fachada con puerta abierta en el lado norte, cuando sabemos, por la documentación que Camargo así lo había dibujado (A.G.S. Marina, Leg. 216). Por eso mismo Lucas Cintora reclamaba, lógicamente, una ventilación exterior, en las fachadas sur y este de lo construido, correspondientes a los dormitorios, que Camargo no contempló y que Pizarro, en su copia, no alteró. Desgraciadamente, el proyecto que Pizarro presentó en 1786 para terminar el Colegio no es conocido o no se ha conservado; sólo tenemos constancia de que lo hizo y presentó, aunque la continuación de las obras le fueron encargadas a Cintora, como es sabido.

Pero, quien finalmente dotó al edificio de otras tres fachadas, ajenas a la principal, la definida con la portada de Figueroa, con sus luces, fue Balbino Marrón en el siglo XIX, aislándolo y limpiándolo de adherencias, como confirman sus planos de Sanlúcar, que se adjuntan en este mismo informe o memoria histórica. 


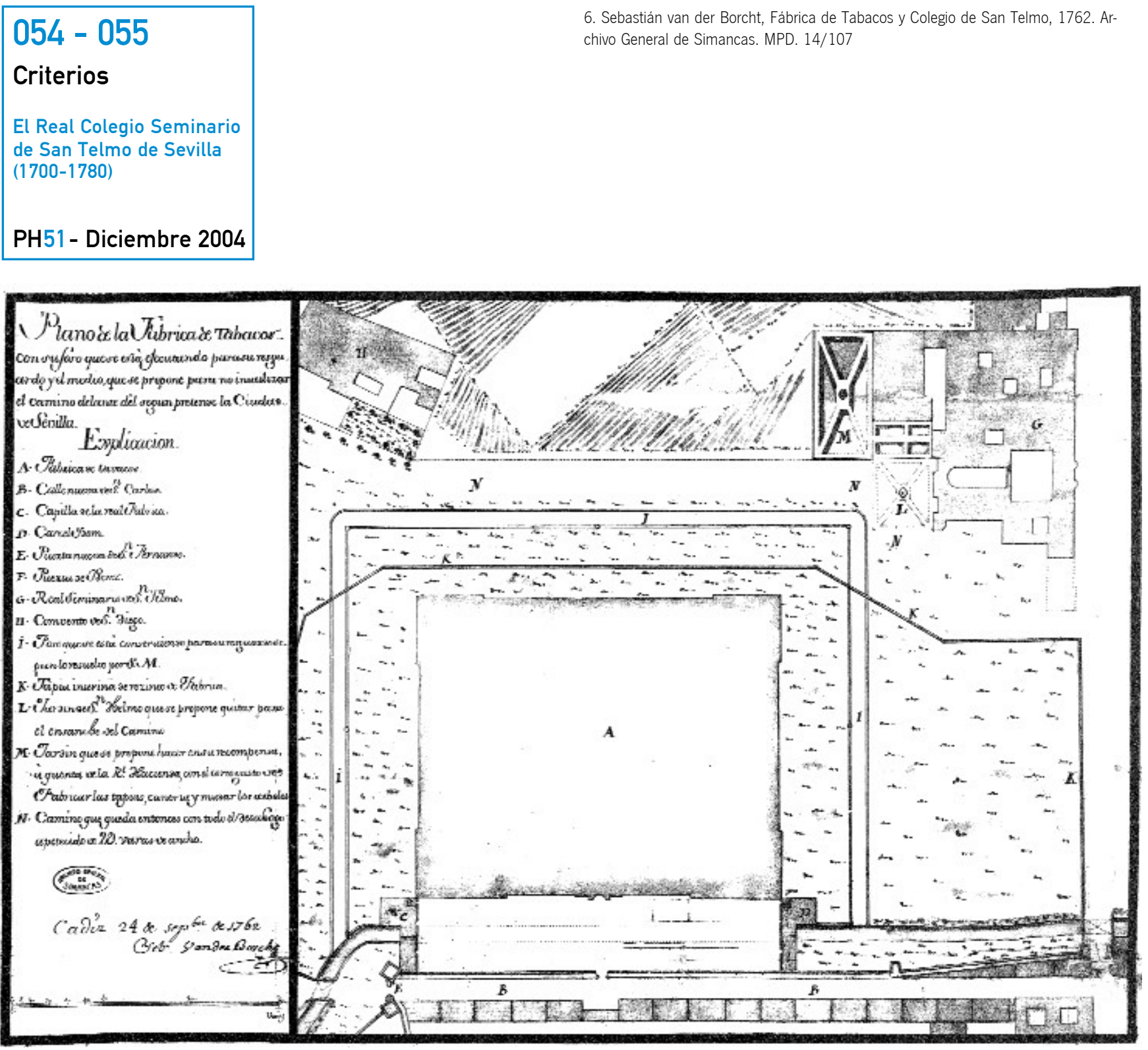

El aparente desorden de ese lado sur, con varios patios y construcciones añadidas a las tres crujías fundamentales y al refectorio, explican bien el complejo proceso constructivo del edificio, obligado a entrar en funcionamiento desde 1681, en el momento mismo de su fundación por Carlos II y, por descontado, antes de estar terminado, lo que justifica, sin duda, que tuvieran que improvisarse, entre las tres crujias y el refectorio y aulas, otras construcciones de servicios necesarias (cocinas, enfermería, ropero, etc.), con sus respectivos patios interiores. Es más, también se usaron los edificios anejos y anteriores del llamado "barrio de San Telmo", propiedad de la Inquisición, por dos razones fundamentales. En primer lugar, porque el colegio debía iniciar sus actividades desde el principio y con ciento cincuenta alumnos, según ordenaba la Cédula Real (y en otra posterior, de 1686, el propio Carlos II autorizaba a que el número de alumnos pudiera ser aumentado de los ciento cincuenta previstos en la cédula fundacional a ciento setenta y cuatro: estos 24 lo serían en calidad de supernumerarios y se limitaba a recoger una situación de hecho ya en esos primeros años del Colegio ${ }^{8}$ ), y profesores, personas de servicio, etc., y necesitaba usar de los mismos, ya fuera como graneros, tahonas, almacenes, dormitorios, vivienda, etc. y, en segundo lugar, porque en el contrato con la Inquisición no sólo se obligaron a un censo perpetuo de renta, sino a mantener las construcciones del "ba- rrio". Es más, durante mucho tiempo, siglos XVII y XVIII, los inquilinos de esos edificios aportaron rentas de alquiler que fueron, en ocasiones, decisivas para la financiación del colegio (al respecto, pueden verse los estudios, ya citados, de M. E. Jiménez y M.C. Mena, entre otros).

La presencia de esas construcciones adheridas al edificio principal, tal como fue proyectado, puede seguirse de forma convincente en la documentación escrita y en la gráfica indirecta durante el siglo XVIII y hasta los dibujos de Marrón en 1849 y siguientes. Es cierto que planos proyectuales del siglo XVII y XVIII del Colegio de San Telmo no se han conservado, a pesar de las numerosas referencias que mencionan sucesivos dibujos, planos y proyectos, con la excepción del de Antonio Camargo, copiado en 1781 por F. Pizarro y de los de 1849 y 1850 de Balbino Marrón, que son fundamentales para conocer la historia del edificio en el período anterior a su intervención. Sin embargo, de los primeros, los indirectos, son muy significativos para la comprensión de la evolución constructiva y compositiva del edificio, ya fueran ocasionados por conflictos legales y jurídicos con la Fábrica de Tabacos o con el Ayuntamiento de Sevilla, o sencillamente porque al dibujar y proyectar la primera, la Fábrica, los ingenieros militares debían representar los alrededores de la misma e incluian el estado de San Telmo, y esto 
${ }^{8}$ Volumen de Copias de Cédulas Reales relativas a San Telmo conservado en A.H.U.S., Cédula Real de 1686, pág. 99

${ }^{9}$ Todos estos planos se adjuntan en la memoria histórica original.

entre los años veinte y los ochenta del siglo XVIII, lo que no es un dato menor ya que sirve precisamente para constatar la evolución constructiva del Colegio aunque sea en sus aspectos más generales o, porque, con ocasión de algún nuevo proyecto, luego no construido, aparece el volumen y planimetría de San Telmo como si estuviera terminado, señal, por otro lado, de que todo el mundo era consciente de la existencia de una traza general desde 1681, aunque no fuera respetada en todos sus detalles, como es lógico que sucediera en un edificio de historia tan compleja y azarosa. Este último caso, el de un edificio proyectado y luego no construido, y que representa, por razones de inmediata proximidad, el de San Telmo como si hubiera sido terminado con su planta rectangular y sus cuatro torres-miradores en las esquinas, aparece en el plano, conservado en A.G.S., G.M.-5862-M.P. y D.XXIII-43, de Antonio Hurtado, para la construcción de un Cuartel para un regimiento de Caballería o Dragones en esta ciudad de Sevilla, de 1786, fecha fundamental por diferentes motivos aducidos hasta ahora.

Del primitivo proyecto, cuya planta estuvo colgada y enmarcada en la propia contaduría del Colegio durante el siglo XVIII, sabemos que se hicieron numerosas copias, muchas de las cuales lo fueron no con fines proyectuales, sino legales. Algunos de los indirectos son muy importantes para seguir el proceso de crecimiento de las obras durante el siglo XVIII y presentan también los volúmenes de edificios añadidos, viejos y nuevos, así como patios de servicios, jardín, lavadero, secadero de ropa, etc., al volumen principal, describiendo así la compleja historia constructiva del edificio cuyas huellas aún están presentes en el plano de Camargo, copiado por Pizarro en 1781. Entre ese tipo de planos, levantados en función de conflictos con la Fábrica de Tabacos o con el Ayuntamiento, es muy importante el de Ignacio Sala (A.G.S.), de 1728, con el proyecto de la Fábrica y el estado en el que se encontraba San Telmo, ya por entonces terminada la iglesia por L. de Figueroa, pero aún por concluir el patio y claustro, así como el zaguán y la portada. Otros planos significativos conservados y que informan globalmente del avance de las obras son los de Diego Bordick, de 1741 (A.G.S.), el de Félix Davalillo y J. Barnola, de 1750 (A.G.S.), los muy importantes de S. Van der Borcht, de 1762 y 1764 (A.G.S.) o el de M. de Taramas, también de 1762 (A.G.S.), además de los muy numerosos relativos al pleito con el Ayuntamiento realizados en torno a 1775 y 1776, cuya documentación se conserva en diferentes archivos (Simancas, Histórico Nacional, Indias, etc. ${ }^{9}$ ).

A partir de 1700 y del informe de Urbizu y del maestro A. Rodríguez, del año anterior, las obras debieron continuar, aunque a ritmo más lento. En 1703, los maestros José Garcia y Juan de Oviedo realizan un informe sobre el estado de las obras en el que señalan que lo construido va correctamente levantado con respecto al plano original, que ya sabemos por A. Rodriguez (1699) que tenía cuatro torres-miradores y una escalera principal de "ocho subidas y reparte en cuatro partes desde la mesa principal", como casi un siglo después acabaría haciéndose, y disponía un eje central con la iglesia, patio principal y portada. Además de obras de cimentación y terminación de la cerca que iba sobre las zanjas perimetrales de cimientos del edificio, no parece que se hiciera mucho más en esos años, quedando en 1703, según J. García y J. de Oviedo (A.G.I, Indiferente 1637), lo siguiente por hacer: "de las sinco partes de la obra solo estan hechas dos", considerando el todo del edificio proyectado como ajustado a los usos y funciones previstos, de tal forma, señalan, que "hecha y acavada toda la obra no sobrará nada de la casa porque todo es menester."

Entre la muerte del maestro Antonio Rodríguez en 1707 y la llegada de Leonardo de Figueroa en 1721 a las obras no se avanzó mucho en nuevas partes del colegio, sino en obras de mantenimiento, cimentación, etc. y en la fachada principal, en la que se situó provisionalmente la iglesia mientras se construía la principal, notablemente sacada de cimientos en esa época. En 1722, Figueroa, junto con Juan T. Díaz, se compromete a construir la iglesia abaratando costes pero cambiando y simplificando el primitivo proyecto, que estaba sacado de cimientos y muy crecido en la cabecera, señalando que "la dejarían a la postura natural de Oriente a Poniente pues en el primer diseño estava atravesada su planta..." (A.P.N.S., L. 5.185). En septiembre de ese año de 1722 las obras de la iglesia habían avanzado mucho y Figueroa propone, según un largo y minucioso informe (A.H.U.S) la continuación de las mismas, construyndo la sacristía al sur de la nueva cabecera de la iglesia y la enfermería al norte, con el fin de cerrar el edificio por esa parte y dejar preparado para su continuación por la crujía este hacia el norte, además de dotar de mayor firmeza a la propia iglesia "que queda por todas partes amparada". Prevé también la construcción del claustro, por diseño de su hijo Matías de Figueroa, a quien se debe también el de la enfermería, así como el resto de las obras, incluida la terminación de la portada y la construcción de diferentes cuartos en el lado norte del patio principal, dejando un patio secundario en el que luego había de proyectar una escalera claustral el maestro A. Camargo en 1779-80, no construida. Toda esta zona y sus obras estaba concluida prácticamente en 1739. Los planos de 1741 de D. Bordick para la Fábrica de Tabacos así lo confirman, además del grabado de Tortolero con la portada y la mitad sur de la fachada principal, aunque este grabado, que debía estar basado en un conocimiento directo del diseño de Leonardo de Figueroa para la portada, representa un remate distinto al que al final se construyó. La Iglesia se inauguró en 1724 y la portada en 1734. Con esta operación, decisiva y la mejor conservada del edificio, los Figueroa consolidaron desde todos los puntos de vista, tipológico, compositivo y de lenguaje, el Colegio de San Telmo. Durante el Lustro Real, Felipe V pudo ver, incluso en su visita al edificio en 1729 , un estado optimista de las obras del Seminario y de su iglesia, cuya ornamentación interior estuvo en manos de algunos de los más importantes artistas activos en Sevilla en esos años y, especialmente, Domingo Martínez, cuya cultura y biblioteca conocemos y que no debía ser muy ajena a la que poseian los Figueroa, incluyendo idénticas referencias a modelos no sólo locales sino también italianos y especialmente al padre Pozzo, cuyos ecos pueden rastrearse sin la menor dificultad en la portada y en las mismas pinturas de Martínez. 


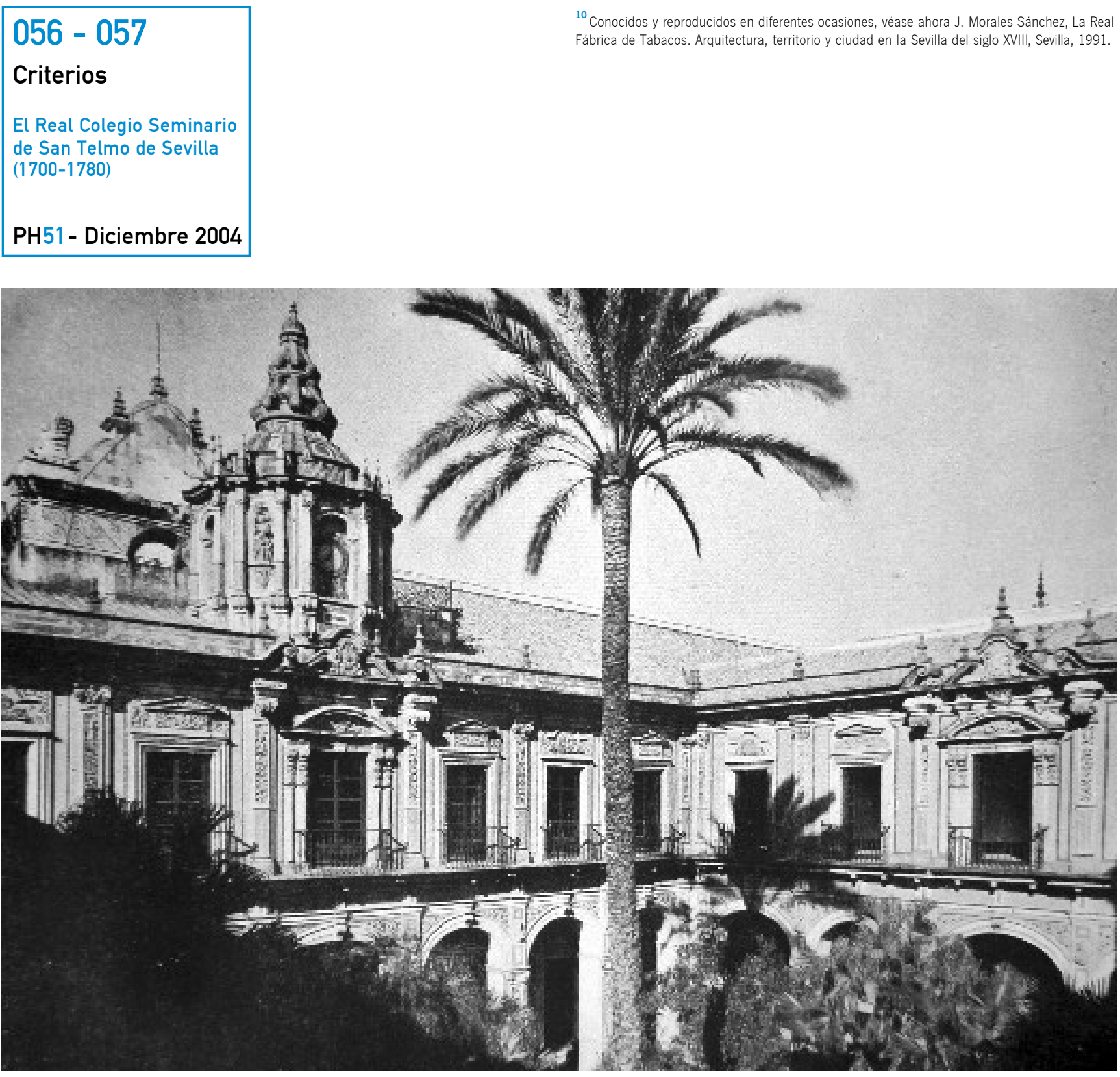

Entre 1740 y 1756, es decir, al final del reinado de Felipe $V$ y durante casi todo el de Fernando $\mathrm{VI}$, las obras realizadas fueron pocas y estuvieron prácticamente paralizadas. Los gastos en esa época fueron los más reducidos en toda la historia del edificio.

En todo caso, varios planos de 1741, de Diego Bordick (A.G.S.) para la Fábrica de $\operatorname{Tabacos}^{10}$, algunos de ellos especialmente cuidados, muestran con claridad lo construido entre 1728 (fecha del plano de I. Sala, ya comentado), casi al final de la vida de Leonardo de Figueroa, y 1740, época en la que dirigió la obra su hijo Matías de Figueroa. Fueron una decena de años decisivos, como sabemos, ya que se cerró el claustro del patio, el zaguán y casi estaba terminada la portada, a falta del remate, según el proyecto de Leonardo de Figueroa, y también se levantaron los cuartos del lado norte a ese eje (iglesia, patio, zaguán, portada), incluyendo la enfermería y diferentes salas, dejando marcado el hueco de un patio, en el que luego Camargo, en 1779-1780, proyectaría una escalera, no realizada. La crujía de la fachada principal llegaba casi hasta los límites que el plano de 1781, de Camargo-Pizarro, da por construidos en esa fecha. Es decir, que cuarenta años después, el edificio había avanzado poco en relación a lo construido por los Figueroa. Sin embargo, los planos de
Bordick, de 1741, ya dibujan sobre el terreno el perfil global de lo que quedaba por hacer, incluyendo, marcada en planta, la torre del noroeste. Es decir, que los Figueroa habian variado el plano en su eje central, pero tipológicamente seguian el primitivo proyecto de 1681

En 1757, coincidiendo con la recuperación económica del Colegio, Rodrigo Márquez de la Plata solicita al rey, en nombre la Universidad de Mareantes, habilitar una Sala de Juntas independiente, porque hasta entonces habian usado "la sala de contaduría", con evidentes incomodidades, según dice, en relación al carácter reservado que debian tener las mismas. Eligen, para dicho fin, Sala de Juntas, "una pieza de este dicho Real Colegio que desde su fundación parece que se labró con este destino y sólo le falta el techo de cielo raso, solado, blanqueo y puertas, que según su construcción le corresponde, pues de ventanas, rexas, y de lo demás que conviene, la advertimos proveida, sin que penetremos la causa de haver dexado nuestros antecesores en calidad de abandonada una pieza tan útil." Se trata de la numerada con el 208 en el plano de Camargo-Pizarro, de 1781, y situada en la crujía principal al oeste, la última construida en esa fechas y que permanecía así en 1781, ya que, como decía en ese año de 1757 el propio Máruqez de la 
7. Patio principal del Colegio-Seminario de San Telmo (1724-1734). En SANCHO CORBACHO, A. Arquitectura Barroca Sevillana, Madrid: Consejo Superior de Investigaciones Científicas, 1984, lámina 40

8. Capilla del Colegio-Seminario de San Telmo (1724-1734). En SANCHO CORBA$\mathrm{CHO}, \mathrm{A}$. Arquitectura Barroca Sevillana, Madrid: Consejo Superior de Investigaciones Científicas, 1984, lámina 41

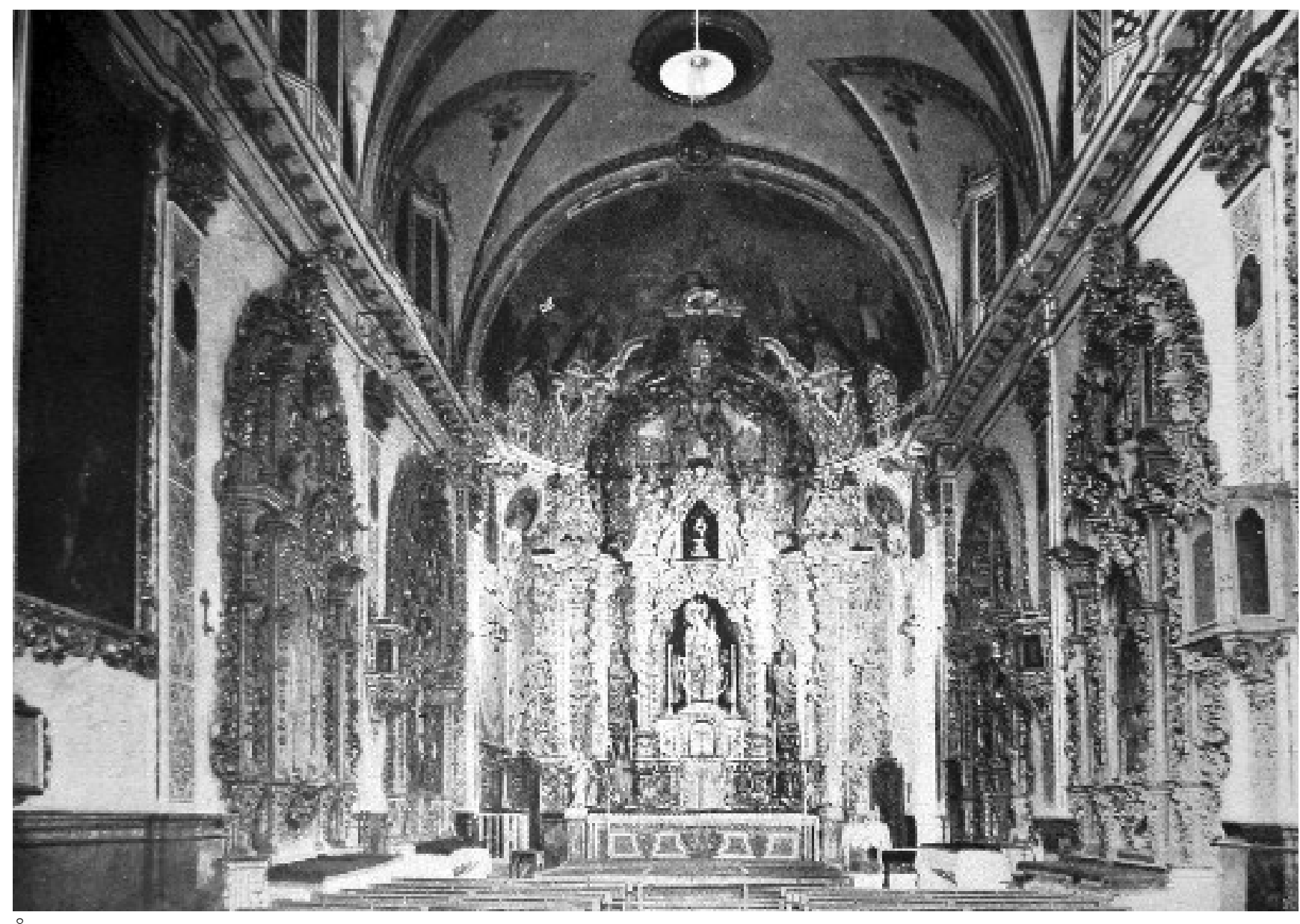

Plata, se había "quedado la casa a medio hazer."(A.G.S. Marina, Leg. 215). Esta sala es prácticamente lo único que se construye entre 1740 y 1757, año, este último, en el que estaba terminada, pero no adecentada para usarla.

Los años sesenta son años, fundamentalmente, de pleitos con la Fábrica de Tabacos y con el Ayuntamiento de la ciudad, pero también lo son, como consecuencia de aquéllos, de la aparición de numerosos planos en los que es representado el Colegio de San Telmo tanto en sus trazas generales como en el bloque de lo construido, siempre en función de los pleitos mencionados y no con carácter proyectual, lo que, sin embargo, no les resta valor documental. Ya en 1760, la Fábrica de Tabacos pretendia construir un foso que ocupaba no sólo terrenos de San Telmo, sino que afectaba también al Camino Real que circulaba entre ambos edificios. San Telmo y el Ayuntamiento de Sevilla, en esta ocasión unidos, protestaron. En 1762, el ingeniero Van der Borcht respondía con un informe y plano (A.G.S., M.P. y D., XIV-107), proponiendo desplazar simplemente el jardin de San Telmo de su lugar, hacia una zona más al sureste, dibujando y asumiendo el primitivo proyecto de San Telmo, de 1681, dibujado con línea de puntos. M. de Taramas, por encargo del Cabildo secular de la ciudad, confirmaba
(A.G.S., M.P. y D., XIV-108) que la obra del foso afectaba tanto a los terrenos propiedad de San Telmo, como a los intereses de la ciudad al invadir el Camino Real. En 1764, Van der Borcht propone una alternativa, haciendo "esférico el foso", atendiendo así a las presiones de San Telmo y del Asistente de la ciudad, Ramón de Larumbe, para no afectar ni al primero ni al Camino Real que, según este último, quedaría alterado por el mencionado foso de la Fábrica de Tabacos, que ocuparía el Camino Real de los Puertos, "deformando así la entrada a la ciudad por aquella parte." (A.G.S., Marina, Leg. 215). Tanto el plano de Taramas, como el de Van der Borcht, el primero de 1762 y el segundo de 1764, representan, al tiempo, el plano de San Telmo, tal como estaba en esos momentos (incluido el patio que luego había de ocupar la escalera proyectada por Camargo, en 1780, como principal del edificio y no construida) y, además, Van der Borcht afirma, como ya sabemos, que dibuja San Telmo en función de una copia del plano antiguo de 1681 que tiene en su poder. En esta ocasión, el Asistente de Sevilla y San Telmo se enfrentaron juntos contra las pretensiones de la Fábrica de Tabacos, lo que no ocurriría diez años después, a pesar de estos antecedentes, aunque ya en el mismo año de 1764 , Larumbe, ante la presión de la Fábrica de Tabacos, pretendió mantener el camino real a costa de San Telmo. Sin embargo, Carlos III, 


\section{$058-059$ Criterios \\ El Real Colegio Seminario de San Telmo de Sevilla (1700-1780) \\ PH51 - Diciembre 2004}

por medio de Esquilache, mandaba parar las obras del foso en el mismo año de 1764, "cuando faltaba poco para concluirse". Ese mismo año, y aprovechando la ocasión de la disputa, el Colegio de San Telmo solicita al monarca el aumento de sus presupuestos con el fin de terminar las obras y el edificio, así, dicen sus responsables, no sólo podría acoger más huérfanos, sino que se evitarían situaciones como la ya considerada, con un foso y un camino que pretendian invadir un terreno en el que el Colegio ya había "concluido los cimientos para continuar la suya." En 1765, Carlos III, aprueba la continuación de la obra para que "siga por donde estaba delineada", lo que volvió a ratificar en 1769 (A.G.S., Marina, Leg. 215).

Aunque sea sólo una curiosidad, pero que habrá de tener importantes consecuencias en el futuro de la historia proyectual del edificio por la importancia que acabaría adquiriendo el protagonista de esta historia, Francisco Pizarro, que había sido colegial de San Telmo, era liberado, ese año de 1764, de su cautiverio en Argel a cambio de 17.000 reales de vellón, gracias a un donativo anónimo de 30. 000 reales, es decir, casi la mitad de lo invertido en obras en el edificio entre 1740 y 1756, como ya sabemos. El anónimo donante indicaba que lo sobrante después de su liberación se emplease en dorar dos marcos "de esquisita talla" que adornaban dos pinturas de Domingo Martínez en la iglesia del Colegio (La disputa en el Templo y Entrada en Jerusalén de Nuestro Redentor, según las menciona el documento y se conservan, ambas de $1725^{11}$ ).

Todavía a principios de 1775, Rodrigo Márquez de la Plata, ya Juez Conservador del Colegio de San Telmo, se quejaba al rey de que el Teniente de Asistente de la ciudad de Sevilla, F. Ruiz de Albornoz, había plantado árboles y abierto hoyos para un camino en terrenos del Colegio, "estando mandado continuar la obra de su Edificio" por el propio monarca. El rey, en abril de ese mismo año, resolvió, a consulta, al respecto, del Consejo de Indias, "se deje à el Colegio Seminario de Santelmo de Sevilla, libre uso del terreno que tiene acreditado corresponderle." (A.G.S., Marina, Leg. 217). Los árboles habian sido plantados, por iniciativa de Francisco Ruiz de Albornoz, en 1774, pero, por orden del rey, en 1775 fueron retirados, se reabrieron zanjas para cimientos y se labró una cerca que delimitaba el espacio que quedaba por construir del edificio.

En septiembre de 1777, Carlos III resolvía, de nuevo, desde La Granja de San IIdefonso, y a consultas del Consejo de Indias, que ante el nuevo intento de Francisco Ruiz de Albornoz, Teniente Primero de Asistente de Sevilla, de plantar árboles, "en el sitio o área propio de ese Real Colegio de San Telmo, y destinado para concluirse la obra con arreglo al Plan aprobado el año de 1681", resolvía, dice la documentación, que "de ningún modo, ni con ningún motivo se impida al Seminario el uso y propiedad del referido terreno, ni la continuación de la citada obra, hasta su perfección, dejándolo libre y desembarazado para los expresados fines..." ${ }^{12}$. La resolución regia cerraba así la intención del ayuntamiento de Sevilla de adornar con una arboleda un "camino Real" entre la Fá-
${ }^{11}$ Sobre Domingo Martínez pueden consultarse los estudios de S. Soro (1982), E. Valdivieso (1986) y A.M. Aranda Bernal (1993), entre otros.

${ }^{12}$ A.G.S., Marina, Leg. 217.

${ }^{13}$ A.G.S., Marina, L. 217 (1775). La mencionada indicación sobre lo que aún quedaba por construir en la fachada y que el propio Francisco Ruiz de ALbornoz admitia que asi era iba en contra de sus otros argumentos, muchos de ellos inciertos y otros malintencionados, sobre todo los relativos a la propiedad y ventas sucesivas de esos terrenos, los previstos para la terminación del edificio del Colegio de San Telmo, como demuestra la documentación conservada.

brica de Tabacos y San Telmo, asunto que ya había originados polémicas y enfrentamientos con anterioridad, dando lugar a varios planos conservados (A.G.S. y A.G.I.). Carlos III y el Consejo de Indias consideraban que el edificio estaba por completarse de acuerdo al plano de 1681 y que nada debía impedir su terminación, ni siquiera un camino arbolado, habiendo aprobado el monarca la "continuación de su fábrica", esa, precisamente, que iniciada en 1681, iba marcada en su perímetro en tantos planos conservados, aunque no directamente proyectuales, antes del de 1781, e incluso en el presentado en 1776 por Antonio de Figueroa y en el anteriormente mencionado de 1775 , que no conocemos, pero que se cita como "adaptado al antiguo". Las razones aducidas en contra por el Teniente de Asistente de Sevilla se basaban en que el terreno dispuesto para su construcción fue aprobado en el siglo anterior, el XVII, como sabemos, y que, sin embargo, la casa de San Telmo, estaba ya concluida "en el mismo siglo" (el XVII) y que nunca se había pensado "en darla la extensión, que ahora pretende", lo que no sólo iba en contra de la evidencia de los planos, de las cédulas reales y otros documentos, sino en contra mismo de lo levantado en el siglo XVIII hasta esas fechas de 1775-1777. No cabe duda de que los argumentos esgrimidos por el Teniente de Asistente de Sevilla eran insólitos, dando por terminado el edificio en el propio siglo XVII, es decir, entre 1681 y 1700, sino que iban en contra de otra afirmación suya en el mismo documento según la cual a la fachada -se refiere a la única existente como tal, es decir, la principal- le faltaban "como unas quarenta varas, que manifiestan los dentellones, que se dejaron para proseguirla"13 (lo que era cierto e incluia la torre del noroeste) y en contra también de su afirmación según la cual, de retirar los árboles plantados en el camino, el Colegio Seminario podría "volver a emprehender la apertura de zanja y cimientos sobre el camino", lo que indica claramente que ya habian sido realizados con anterioridad. Así, sumando a la evidencia de los dibujos indirectos, generados precisamente por la obra de la Fábrica de Tabacos a partir de 1728, por los sucesivos litigios entre ésta y San Telmo, y entre ambas y el Ayuntamiento ya en la década de los años sesenta del siglo XVIII, además de la constantación de lo que faltaba por construir de la fachada principal para completarla y las zanjas y cimientos abiertos en la zona que coincidía con el camino que se pretendía abrir y embellecer con árboles, así, decía, puede concluirse que la existencia de un plano y un programa general, modificado fundamentalmente en tiempos de Leonardo de Figueroa, presidió siempre todas las actuaciones constructivas en San Telmo durante el siglo XVIII y aún después, en la época de Balbino Marrón.

Fue ese proyecto, por el que se guiaba San Telmo, el usado por el Juez Protector del Colegio, Rodrigo Márquez de la Plata, para reabrir, en 1775 (A.G.S., Marina, L. 217), las zanjas en los límites proyectados para el edificio del colegio y levantar, provisionalmente, tapias en ellas, frente a las intenciones y hechos consumados por el Ayuntamiento ya que Ruiz de Albornoz abrió "hoyos en el Area del edificio de la Casa". Márquez de la Plata, para tapar hoyos, reabrir zanjas de cimientos y levantar tapias sobre ellos, decía que hacía "casi un siglo que se abrió de cimientos en virtud del plan apro- 
9. Manuel Coelho. Plano de la situación y contornos de la Real Fábrica nueva del tabaco con sus adherencias, 1771. Archivo General de Simancas. MPD. 23/61

bado por V.M. el (año) de 1681 y así ni hublo despojo, ni tuvo motivo para suponerlo el Theniente: que en su intrusión y competencia procedió con equivocación y tropelía...". En este mismo documento de 1777, que transcribe otro de 1775, Márquez de la Plata, proporciona otro dato muy interesante al respecto del origen del proyecto: "que aunque la Escritura de Dacion á Tributo del terreno no se otorgó hasta 13 de mayo de 1683, por las muchas diligencias que precedieron á su otorgamiento; se eligió el sitio citado desde el de 1681; y pudo hacerse el Plano referido, sin este requisito, aunque con él, entró y lo está en la propiedad, y posesión del seminario: que es cierto que este ha vendido varias aranzadas de tierra que sobraban de un Barrio entero que compró la Universidad de Mareantes; pero que jamás tocó al terreno señalado por el Theniente (se refiere a Ruiz de Albornoz) como Camino Real, y por el Colegio, como delineado y asiento para su Fábrica: sin agravio de Persona ni Comunidad alguna; según todo ello se convence del Plan nuevo adjunto, arreglado al antiguo aprobado por V. M. que es el que demuestra la realidad de este informe..." (A.G.S., Marina, L. 217).

Es decir, que con motivo de estos informes y debates, además de los dibujos que se adjuntan (A.G.S. y A.G.I.), hubo, según la documentación, dos "planos nuevos", arreglados al antiguo, es decir, que presentaban el plan general con las transformaciones posteriores y lo que quedaba por hacer. Uno de ellos sabemos que fue realizado por Antonio de Figueroa en 1776 y el otro es éste mencionado de 1775, que no sería extraño que fuera del mismo arquitecto. El mismo informe del Juez Conservador del Colegio, Márquez de la Plata, de 1775, indica que las pretensiones de Albornoz no pueden ni deben afectar a "la continuación de la obra hasta su perfección, encargada repetidas veces por V. M. con arreglo al citado Plan...". El caso es que en 1777, el asunto estaba resuelto: la Asistencia de Sevilla había retirado "los árboles plantados" y el Seminario "cerrado, y labrado el sitio de la Disputa...".

No deja de ser curioso, sin embargo, que la ciudad de Sevilla, por medio de su teniente de Asistente, durante la Ilustración, estuviera en contra del Colegio de San Telmo, de su terminación como bloque regular, prefiriendo un breve fragmento de camino arbolado que un edificio acabado, pieza fundamental tanto desde un punto de vista arquitectónico como urbanístico (y esto último no tanto gracias a proyectos ilustrados, cuanto a la iniciativa de Felipe $V$ de construir la Fábrica de Tabacos y de abrir nuevos caminos al río motivados por la fundamental actividad y presencia urbana de aquélla), con independencia de su función docente y de formación de pilotos para la flota. El Colegio de San Telmo, con el apoyo del Carlos III y de Manuel de Roda, logró salvar esta circunstancia frente a las intenciones de la ciudad, aunque es cierto que sólo con los Montpensier, y ya a partir de mediados del siglo XIX, San Telmo logró su culminación. Casi podría afirmarse que Sevilla posee, a pesar suyo, una "arquitectura propia de la ciudad", en el sentido en el que lo usaba Aldo Rossi, gracias, en primer lugar a la Corona y, después, a la iniciativa privada de los Montpensier.

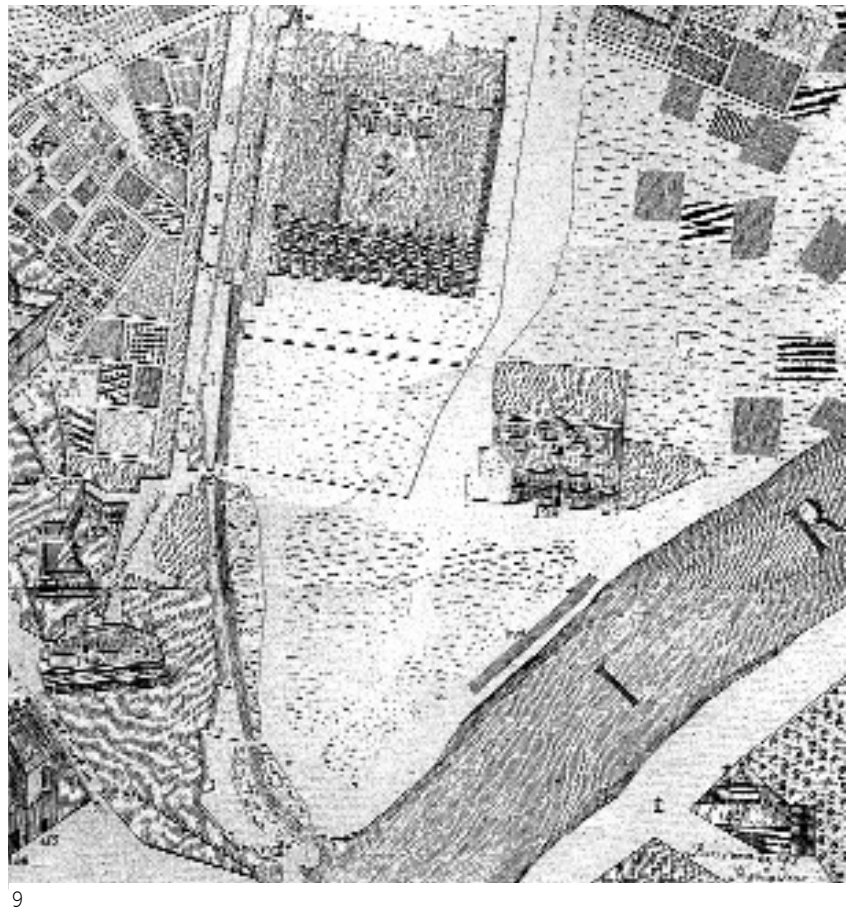

En todo caso, durante la segunda mitad de los años setenta del siglo XVIII sabemos que hubo al menos tres proyectos para terminar el edificio, "variados" o "adaptados" al antiguo de 1681. Uno de 1755, del que no se menciona el autor; otro, el segundo, de Antonio de Figueroa, mencionado pero no conocido y que no es imposible que pudiera ser el autor del de el año anterior y, por fin, el de Antonio Camargo, de 1779-1780, carpintero y alarife conocido de la ciudad de Sevilla y responsable de las obras de su profesión en San Telmo en esos años y aún después. El de Camargo es muy importante porque es el único proyectual que se ha conservado, si bien a través de la copia del mismo que hizo Francisco Pizarro en 1781 y que se estudia en otro apartado de esta misma memoria histórica.

Según la documentación del Archivo de Simancas (A.G.S., Marina, Leg. 216), Camargo recibió en 1779 el encargo de realizar diferentes planos del edificio, en los que dice haber empleado ocho meses. En abril dice haberlos enviado a José Gálvez (Consejo de Indias) y, a través suyo, al Carlos III, que los vio y aprobó, ordenando que se le pagase el trabajo. En abril de 1780, Camargo, se negaba a dar una copia de los planos (enviados al Consejo y al Rey) al contador de San Telmo, Francisco de Tuero, por desconfianza del uso que pudiera hacer de ellos. Las razones de ese comportamiento y la descripción de lo realizado las aduce en un inapreciable documento de abril de 1780 el propio Camargo, que resumidamente dice que los planos enviados a Gálvez y a Carlos III eran "una demostración del actual estado de aquél (se refiere, claro está, al Colegio de San Telmo) edificio y fines a que está destinada cada una de las piezas que la componen. Otra de las divisiones más adaptables a su mejor aprovechamiento, variadas 


\section{$060-061$ Criterios}

El Real Colegio Seminario de San Telmo de Sevilla $(1700-1780)$

\section{PH51 - Diciembre 2004}

en mucha parte las actuales. Otra de su principal fachada distinguiendo la parte que le falta (se refiere al remate de la portada). Y la última de otra fachada que corresponde al frente de la ciudad y se ha formado a precaución de que por esta circunstancia convenga en aquel costado la obra que se demuestra." (Estos planos fueron copiados por Pizarro, aunque sólo se conserva el segundo, el relativo al proyecto de terminación, sin hacerse eco en él de la fachada que Camargo había ideado para la fachada norte, de la que incluía también un alzado, como él mismo dice).

En el mencionado informe, el alarife y carpintero, Camargo, continúa, refiriéndose a sí mismo: "El maestro encargado de estos planos es un alarife de Sevilla que vive del trabajo que le ofrecen las obras particulares de aquel pueblo, donde está acreditado; y por lo mismo se le buscó para esta operación...". Se queja, después y en consecuencia, de que la han pagado poco, estimando su trabajo en mucho más ya que empleó, dice, ocho meses, "en medir el edificio, sacar en borrador los planos, copiarlos en limpio, ponerlos en sus cajas como van y tantear el costo ( es decir, hacer el presupuesto) del resto de la obra demostrada...". La queja de Camargo iba dirigida contra el Contador del Colegio, Antonio de Tuero, que no le pagaba lo que el rey había ordenado. En junio de 1780, el propio Camargo dice haber entregado unos planos, no la copia en limpio de su trabajo, a Jorge Leyrens, diputado del Colegio de San Telmo, para que los depositara en la Contaduría, pero se negaba a hacerlo a Tuero, el contador, ya que era "concuñado de Francisco Pizarro" y "sabía ocultaba particulares fines." El mismo Camargo, el 20 de junio de ese año de 1780, afirma que esos "particulares fines" permitían inferir "que todo fue un empeño del mencionado Contador para darme que merecer y para que instruyéndose Pizarro de estos documentos quede espuesto mi trabajo a la censura de un hombre poco afecto, y menos inteligente en esta materia, y que tal vez disponga medios que me extrechen a separarme del nombramiento de Maestro del Colegio, que es lo que vivamente desean porque saben muy bien que no soy capaz de inclinarme a desasiertos ni a cooperar en cosa que se oponga a beneficio de la Obra Pía."

El diputado del Colegio, Jorge Leyrens, se convierte en protector de Camargo frente a los intereses de Pizarro y su concuñado Antonio de Tuero. Las peticiones y amenazas de este último debieron ser suficientemente convincentes, aunque no del todo, como se verá. Tuero reclama los dos "planos (de Camargo) que abrazan el todo del edificio y de la obra proyectada" y "dos diseños (también de Camargo, y antes descritos por él mismo) del remate de la puerta principal y una parte de lo exterior de la fachada", dibujos a los que Tuero añade la petición, bajo amenazas, de "Cuatro o cinco pliegos en que tiene con individualidad el aprecio que le encargaron del costo de cada una de las piezas contenidas en el citado plano de la obra nueva, reservando todo en su poder con la mira de precisar a que él y no otro maestro intervenga en ella, Ilegado el caso de hacerse...". La observación de Tuero no deja de ser sig-
${ }^{14}$ Siguen siendo documentos contenidos en el Legajo 216, Marina, del Archivo de Simancas.

nificativa, aunque volvió a solicitar, con amenazas de cárcel tanto para Camargo como para el Diputado del Colegio J. Leyrens, "copias del Plano de la obra interior que falta para concluir esta Real Casa y de los dos cortos diseños del remate de la puerta principal y una parte de lo exterior de la fachada que debe hacerse frente a la Puerta de Xerez...". ${ }^{14}$

Es curioso que, cuando Pizarro logra finalmente acceder a los planos, en sucio, eso sí, de Camargo, para hacer su copia, conocida y conservada, de 1781, no refleje la puerta en la fachada, ni la misma fachada, norte frente a la de Xerez y que "debía hacerse". Es posible que copiara mal, debido a las dificultades puestas por Camargo, que sólo entregó al Colegio, a su Contador, planos a lápiz, borradores de los enviados en limpio a Gálvez y al Rey, pero más difícil resulta el error si se hace caso a la observación del propio Tuero de que era una "fachada que debe hacerse", aunque tal vez hubiera que convenir con las palabras, sin duda interesadas de Camargo, sabedor de que competía con un candidato poderoso como Pizarro para hacerse cargo de las obras, de que se trataba de "un hombre...poco inteligente en esta materia...", como ya he señalado. Sea como fuere, lo cierto es que al final ni Camargo ni Pizarro dirigieron las obras, pocas, que habrian de realizarse en esos años y en los posteriores, sino L. Cintora.

Leyrens, el protector de Camargo en este asunto, tenía razones sobradas para desconfiar de las peticiones de Tuero, por sus relaciones con Pizarro. Aceptó que Camargo entregara sus planos, pero no al Contador, sino que fueran depositadas directamente en el "Arca de Tres Llaves". Como Tuero amenazó con "ponerles presos" a los dos, Leyrens, en su descargo, afirma (A.G.S., Marina, Leg. 216), entre otras cosas, que "en el cuarto en el que está el Arca de Tres Llaves estuvo siempre el primitivo plan del Colegio..., custodiado con una puerta de tres llaves..." y añade que lo que movía al Contador, Antonio de Tuero, que poseía una de las llaves, "Es recogerlos y entregarlos a su concuñado Don Francisco Pizarro maestro artillero segun y como lo hizo con el que formo el año de 1776 el maestro Antonio de Figueroa, pues luego que los presento este, los paso el contador a sus manos y puestas varias adiciones sin inteligencia devida solicito premio por su trabajo como consta en el memorial que para en la contaduria..." .

Finalmente, Leyrens, y como consecuencia, Camargo, que se autodenomina en otro texto contemporáneo "noble Albañil y carpintero", entregaron una copia a lápiz, un borrador, de los planos. La amenaza de cárcel por parte de Tuero y Márquez de la Plata debió ser considerada por aquéllos, pero no tanto como para entregar una copia en limpio. Pizarro usó los borradores mencionados, que Cintora también vio y consideró insuficientes, además de que faltaba el presupuesto, "cuatro o cinco pliegos", de las llamadas obras interiores para la terminación del edificio. Sólo se conserva la copia de la planta con el proyecto de terminación de Camargo, realizada, por fin, por Pizarro en 1781. 


\section{Fuentes documentales y bibliográficas}

Abono de sueldo a Julián Romero, jardinero del colegio de San Telmo, Sevilla. 1735 Archivo General de Simancas, Secretaria y Superintendencia de Hacienda, 1/122 (686-696)

Acta notarial del testamento de la Infanta de España doña María Luisa Fernanda de Borbón y Borbón, duquesa viuda de Montpensier, realizada por el notario don IIdefonso Calderón y Cubas. 1897, 7 abril. Real Biblioteca, II/4042 (24)

Artículos adicionales a las ordenanzas de los Colegios de San Telmo de Sevilla y Málaga, relativos al establecimiento de porcionistas en dichos Colegios. 1790. Archivo Museo Naval, F181/42

Auto a petición de Pedro Fernández de Villacañas, fiel y ministro de la renta del diez mo de la cal, teja y ladrillo, contra un carretero por no haber registrado las carretadas que descargó en el Colegio Seminario de San Telmo. 1718. Archivo General de Palacio, Administraciones Patrimoniales, Reales Alcázares de Sevilla, caja 347, exp. 12

Certificación de Francisco Antonio de Tuero, contador de San Telmo, de lo pagado y gastado de los 120.000 reales que el rey concedía anualmente al colegio. 1781 Archivo General de Simancas, Secretaria de Marina, leg. 216

Cesión institucional del Palacio de San Telmo a la Junta de Andalucía. 1989. Archivo General Arzobispado Sevilla, leg. 730, núm. 6 (según FALCÓN, T. El Palacio..., p. 259, n. 2)

Circunstancias que han de concurrir en los niños que se admitan a plaza de seminaristas del Colegio de San Telmo de Sevilla. 1767- 1797 (entre). Real Biblioteca, II/2834, f. $1 \mathrm{r}-2 \mathrm{v}$

Colegio de San Telmo. Copia de las cédulas reales de Carlos II. 1681. Real Academia de la Historia, 9/3700/2, Jesuitas, T. 127

Compendio de la arte de la navegación que D. Pedro Manuel Cedillo dio a la pública luz para la enseñanza de los niños de dicho Real Colegio de San Telmo. Se villa, 1730?. Real Biblioteca X/303

Compendio de las más individuales noticias de el Real Colegio Seminario de San Telmo de niños huérfanos, extra-muros de Sevilla, su instituto, orden, con que se gobierna, y los que han salido aprovechados hijos de él, con otras cosas, que adelante se expressaran. 1743 (posterior a esta fecha, según se deduce del texto). B.N.M., R/38933; Biblioteca de la Universidad de Sevilla, Estante 111, núm. 120; Real Academia de la Historia, 5/898(2)

Consulta del Consejo de Indias a Carlos III sobre el deber de José Jaque Capillas de contribuir con 50 pesos al Seminario de San Telmo en Sevilla, como es costumbre entre cuantos toman posesión de un cargo a través del Consejo de Indias, aunque no haya jurado su cargo en Cádiz. Resolución del Rey. 1770, 25 enero. Real Biblioteca, II/2757, fols. 274r-276v

Copia del pedimento de D. Juan José Miguel de Flores que en respuesta de la ale gación del Sr. Fiscal de la Suprema General Inquisición en los Autos que en ella sigue el Real Colegio de San Telmo de Sevilla, con el fisco del Tribunal de la Inquisición de Sevilla, sobre a qué clase de tributo pertenece el de 9.000 reales que con nombre de perpetuo le paga dicho colegio. 1780. Real Academia de la Historia, 9/4825, fols. $84 \mathrm{r}-108 \mathrm{v}$

Copias de las Cédulas Reales que SS.MM. D. Carlos 2, D. Felipe V, D. Luis I y D. Fernando VI han mandado expedir para la fundación y conservación del Real Colegio Seminario de niños huérfanos, fundados en el sitio de San Telmo... Sevilla,
1755. Real Biblioteca, X/744; Real Academia de la Historia, 9/3700/2 y 4/226; Archivo Museo Naval, mss. 33 (facsímil en Museo Naval de Madrid. Colección de documentos y manuscritos compilados por Fernández de Navarrete, Liechtenstein, 1971, vol. 24, $2^{\text {a }}$ parte, pp. 1337-1484)

Cuentas de Juan Antonio Palomera, recibidor de granos en el sitio de San Telmo en Sevilla, para el aprovisionamiento del ejército. 1642-1643. Archivo General de Simancas, Contaduría Mayor de Cuentas, $3^{\text {a }}$ época, 989

Cuentas de Juan Antonio Palomera, recibidor de granos para la provisión de los reales ejércitos en el sitio de San Telmo del río de Sevilla, por nombramiento del licenciado Juan de la Calle. 1641-1642. Archivo General de Simancas, Contaduría Mayor de Cuentas, $3^{a}$ época, 1457

Decreto de supresión del Colegio de San Telmo de Sevilla. 1841. Archivo Museo Naval, mss. 1210 , doc. 1, fols. 1-4v

Demostración de los puntos sobre que a consecuencia de resolución de S. M. [...] han de ser examinados los que pretendan el empleo de maestro de la primera clase de mathemáticas del Real Colegio Seminario de San Telmo. Sevilla, 1783. Archivo Museo Naval, F113

Descripción de las festivas demostraciones de júbilo con que el Real Seminario de... San Telmo y Universidad de Mareantes de Sevilla, celebraron en los días 17 y 18 de diciembre de 1783 el nacimiento de los... Infantes... de España D. Carlos y D. Felipe y la paz ajustada con Inglaterra. 1783. B.N.M., 2/61095 (8); Real Academia de la Historia, 23-22876

Discurso que para la apertura de los certámenes públicos del Real Colegio de San Telmo de Sevilla del año de 1793 dixo su tercer catedrático don Joseph Rebollo. Sevilla, 1793. Archivo Museo Naval?, 8248

Documento de D. Franco Xavier de Vega sobre el buen régimen y gobierno de una secretaría o contaduría para la expedición de los negocios de San Telmo. 1780, h. Real Academia de la Historia, 9/4825, fols. 63r-83v

Don Joaquin Farfán de los Godos, subdiácono de Sevilla, con los diputados del Colegio de San Telmo, sobre que no se le impidiese entrar en dicho colegio. 1764. Archivo Histórico Nacional, Consejos, leg. 20.208, núm. 8

El colegio de San Telmo, con don Isidro Miró y don Sebastián Clemente Francia, como marido de doña Maria Miró, apoderado en Cádiz de los caudales y limosnas pertenecientes a dicho colegio, y don Pedro Sánchez Bernal, escribano de cámara de esta tribunal, sobre reintegro del alcance de cuentas de dicha administración. 1765-1772. Archivo Histórico Nacional, Consejos, leg. 20.205, exp. 1

El secretario del despacho de Marina da las gracias al arzobispo de Sevilla, por encargo del rey, por haber entregado al director del Colegio de San Telmo de Sevilla el dinero necesario (32.632 reales) para la construcción del vestuario de los alumnos. 1818 , abril. Archivo Museo Naval, mss. 1377, doc. 5, fols. 34-43

El seminario de San Telmo de Sevilla contra su administrador, por la entrega de los 28.369 reales y 2 octavos de plata procedentes de la recaudación de los derechos que tiene el seminario de San Telmo sobre los permisos despachados en Canarias a las naves que viajan de registro a América. 1767-1772. Archivo Histórico Nacional, Consejos, leg. 20.281, exp. 4

Exercicios literarios de los alumnos del Real Colegio de San Telmo en Sevilla. 1805. Archivo Museo Naval, F153/19 y F214/20

Exercicios literarios de los alumnos del Real Colegio de San Telmo de Sevilla, que principiaran el dia 20 de febrero de este año de 1804, con asistencia de sus catedráticos y maestros presididos por su director el capitán de fragata don Adrián 


\section{$062-063$}

\section{Criterios}

El Real Colegio Seminario

de San Telmo de Sevilla

$(1700-1780)$

\section{PH51 - Diciembre 2004}

María García de Castro. Sevilla, 1804. Real Biblioteca, XIX/4824; Archivo Museo Naval, F53

Exercicios literarios de los alumnos del Real Colegio de San Telmo en Sevilla. SeviIla, 1802. Real Biblioteca, VIII/9351; Archivo Museo Naval, F59

Exercicios literarios de los alumnos del Real Colegio de San Telmo en Sevilla. SeviIla, 1796. Real Biblioteca, VIII/10833

Exercicios literarios de los alumnos del Real Colegio de San Telmo en Sevilla. 1800 Archivo Museo Naval, F60

Exercicios literarios de los caballeros porcionistas del Real Colegio de San Telmo de Sevilla, que principiaran el día [...] de febrero de este año de 1800 . Sevilla, 1800 Archivo Museo Naval, IMP-60

Exercicios literarios de los Caballeros Porcionistas del Real Colegio de San Telmo de Sevilla. 1804. Real Biblioteca, VIII/13649; Archivo Museo Naval, F58

Expediente de declaración B.I.C. del palacio de San Telmo. 1967-1968. Archivo Central de la Secretaría de Estado de Cultura, caja 87655 bis, exp. 14

Expediente formado sobre conceder permiso al colegio de San Telmo para celebrar cien corridas en beneficio del colegio. 1793. Archivo Histórico Nacional, Consejos, leg. 1.493, núm. 21

Expediente personal de Joaquín de Alcázar y Arrás, alcaide del palacio de San Telmo. 1855-1858. Archivo General de Palacio, Personal, caja 39, exp. 4

Expediente sobre el nuevo camino que el cabildo secular de Sevilla intentaba abrir en tierras pertenecientes a San Telmo. 1764-769. Archivo General de Simancas, Se cretaria de Marina, leg. 215

Expediente sobre la concesión de otra paja de agua al Real Seminario de San Telmo. 1782. Archivo General de Palacio, Administraciones Patrimoniales, Reales Alcázares de Sevilla, caja 67, exp. 20

Expediente sobre la reclamación de una paja de agua por el Seminario de San Telmo. 1782. Archivo General de Palacio, Administraciones Patrimoniales, Reales Alcázares de Sevilla, caja 65, exp. 24

Extracto de los papeles correspondientes a la universidad de mareantes y al Cole gio de San Telmo de Sevilla. 1789, h. Archivo Museo Naval, mss. 0083

Habiéndose propuesto el Rey con el establecimiento de Porcionistas en los Colegios de San Telmo de Sevilla y Málaga proporcionar a la juventud distinguida de los mismos pueblos y sus inmediatos todos los medios conducentes a una educación y enseñanza correspondiente a la nobleza.... s.a. Archivo Museo Naval, 10570

Informe de Cayetano Gallego Ordoño al marqués de la Ensenada ante la petición del rey de conocer el estado en que se encontraba el seminario. 1746. Archivo Ge neral de Simancas, Secretaría de Marina, leg. 215

Informe del contador general y del fiscal de Nueva España sobre el expediente de colegio de San Telmo en 1785. 1785. Real Academia de la Historia, 9/4825, fols. $2 r-49 v$

Informe del fiscal y contador general de Nueva España sobre la Universidad de mareantes de Sevilla en 1783. 1783. Real Academia de la Historia, 9/4825, fols. 50-62v

Joaquin Farfán, contra el mayordomo del Colegio de San Telmo Joaquín Manuel Viveros, sobre que no se le impidiese el acceso al recinto de San Telmo. 1764. Archivo Histórico Nacional, Consejos, leg. 20.202, exp. 2
La marina y Colegio de San Telmo en el sitio de Sevilla: Ios jefes y oficiales de la Armada Nacional destinados en esta provincia y puerto, se consideran obligados a dar cuenta de su conducta politica y militar... s.a. Madrid, Biblioteca Central Militar, III-3-4-61 (23)

Libramiento del dinero (3.000 reales) para el dorado de las molduras de dos cuadros de la iglesia del seminario: la Disputa en el Templo y la Entrada de Cristo en Jerusalén, gracias a lo cual la iglesia "quedaria con gran hermosura", faltando sólo por dorarse dos retablos. 1764. Archivo General de Simancas, Secretaria de Marina, leg. 215

Memorial del mayordomo y diputados del colegio de San Telmo sobre que se habilite para sala de juntas una pieza del edificio. 1757. Archivo General de Simancas, Secretaría de Marina, leg. 215

Mención al expediente sobre el pago de 9.000 ducados que debe hacer anualmente el colegio seminario de San Telmo al real fisco de la Inquisición de Sevilla, por la compra de diferentes casas, hornos, almacenes y tierras pertenecientes a este tribunal, con las consultas de los consejos de Indias e Inquisición. 1771-1773. Archivo General de Simancas, Secretaria de Marina, leg. 216

Obras. 1554. Ajuste de las cuentas de las obras hechas en San Telmo y colibre por el maestro mayor Enrique Vilaberio (incompleto). 1554. Archivo General de Palacio Según la ficha del fichero (Administrativa, Obras, edificios diversos), "Véase Bellas Artes, leg. 5 (caja carp. $N^{\circ} 28$ )"

Oficio comunicando la rotura de la cañería que lleva el agua al Colegio de San Telmo. 1809. Archivo General de Palacio, Administraciones Patrimoniales, Reales Alcázares de Sevilla, caja 65, exp. 43

Oficio del Real Colegio de San Telmo pidiendo que se corten varios árboles, cuyas raíces dañan las cañerías. 1782. Archivo General de Palacio, Administraciones Patrimoniales, Reales Alcázares de Sevilla, caja 65, exp. 24

Oficio sobre la dirección que ha de llevar la nueva cañería que surte de agua al Colegio de San Telmo. 1808. Archivo General de Palacio, Administraciones Patrimoniales, Reales Alcázares de Sevilla, caja 65, exp. 26

Oración que en la apertura de los exercicios literarios de los alumnos del Real Colegio de San Telmo de la ciudad de Sevila dixo (el 3 de agosto de 1791) su director Don Antonio Ramos. Sevilla, 1791, h.

Ordenanzas de la Universidad de Mareantes que se compone de los dueños de los navios que navegaban en la carrera de Indias, sus capitanes, maestres y pilotos principales: fundadora del Real Colegio Seminario de San Telmo extramuros de la ciudad de Sevilla y administradora perpetura de él en virtud de las Reales Cédulas expedidas para su erección. 1778. Archivo Museo Naval, mss. 0894

Ordenanzas de S.M. para los Reales Colegios de San Telmo de Sevilla y Málaga. Madrid, 1794. Archivo Museo Naval, 306 y dupl. 168; Real Biblioteca, VIII/19285

Ordenanzas para el real colegio de San Telmo de Sevilla. Contiene borradores, anuncios de vacantes, asignaturas que debian impartirse, etc. 1778, posterior. Real Academia de la Historia, 9/4825, fols. 112-464

Ordenanzas para el Real Colegio de San Telmo de Sevilla. Sevilla, 1788. Archivo Museo Naval, F160 y 7770; B.N.M., R/38455

Ordenanzas para el RI. Colegio de San Telmo de Sevilla. Madrid, 1787. Real Biblioteca, X/2184; Archivo General de Simancas, Consejo Supremo de Hacienda, libro 239

Ordenanzas para el RI. Colegio de San Telmo de Sevilla. Madrid, 1786. Real Biblioteca, VI/F/223; Real Academia de la Historia, 4/230 
Permiso para reconstruir la sala de juntas del colegio de San Telmo en Sevilla. El coste ascendia a 15.000 reales. Se remitió a Cádiz para ser aprobado. 1753. Archivo General de Simancas, Secretaria de Marina, leg. 215

Pleito entre la Universidad de Mareantes y el colegio de San Telmo de Sevilla con el fisco de la Inquisición de esta ciudad, para que se les libre del pago de los réditos de un censo. s.a. Archivo Histórico Nacional, Nobleza, Parcent, caja 50, d. 10

Por el Real Colegio Seminario de San Telmo, extramuros de la ciudad de Sevilla, contra el Real Fisco del Tribunal de la Inquisición de dicha ciudad, sobre nulidad de contrato de censo... Madrid, 1790. Vitoria, Seminario Diocesano, Facultad de Teologia, HE-10079

Premios a la virtud distribuidos en el Palacio de San Telmo. Sevilla, 1861. Guadalupe, Biblioteca del Real Monasterio Sa Ma Guadalupe, B 1162 (24)

Proceso sobre la pretensión del obispo de Marruecos de labrar y edificar las tierras que están junto a San Telmo. 1566-1569. Archivo General de Palacio, Administraciones Patrimoniales, Reales Alcázares de Sevilla, caja 8, exp. 42

Proyecto de ley relativo a la enajenación del edificio de San Telmo de Sevilla a favo de la Infanta $\mathrm{D}^{\mathrm{a}} \mathrm{M}^{\mathrm{a}}$ Luisa Fernanda y su esposo el duque de Montpensier presentado por el gobierno. 1849. Archivo del Senado, HIS-0890-03

Proyecto de restauración del palacio de San Telmo, redactado por Guillermo Vázquez Consuegra. 1982. Archivo Central de la Secretaría de Estado de Cultura, exp. 597/82

Reintegro a don José Ortega, director del seminario de San Telmo, de gastos de envío de tres caballos, regalo de S. M. a los grandes duques de Rusia. 1791. Archivo Ge neral de Simancas, Secretaría y Superintendencia de Hacienda, 11/115 (764)

Relación de Manuel de Requena, contador de la universidad de mareantes y real colegio seminario de San Telmo, del gasto anual del referido colegio, ante la solicitud de presidente del tribunal de la Real Audiencia de la Contratación. En el tercer apartado de la relación figuran los gastos de reparos de obras realizadas en el colegio entre 1757 y 1761. 1762. Archivo General de Simancas, Secretaría de Marina, leg. 217

Representación del Seminario de San Telmo, sobre que se le mantenga en la posesión inmemorial de la cantidad de agua que hasta aora ha tenido. 1783. Archivo General de Simancas, Secretaría de Marina, leg. 217

Resolución de que se deje libre y desembarazado al real colegio seminario de San Telmo de Sevilla un terreno comprendido en una arboleda que se está plantando. 1789. Archivo Histórico Nacional, Consejos, leg. 1.257

Resolución del rey para que no se impida al colegio el uso y propiedad del terreno, n la continuación de la obra que ha de hacerse en él, con arreglo al plan del año 1681 dejándolo libre y desembarazado del plantío que intentó hacer el teniente de asistente de Sevilla en 1774. 1744. Archivo General de Simancas, Secretaría de Marina, leg. 217

San Telmo: recuerdo del $1^{\circ}$ de enero de 1861. Sevilla, 1861. B.N.M., 1/243375; Real Biblioteca, VIII/5914 P; Museo Romántico, Madrid, IX-11 núm. 4

Sobre agregaciones de los colegios de San Telmo de Sevilla y Málaga a la jurisdicción castrense. 1795. Archivo Histórico Nacional, Consejos, leg. 16.215

Sobre la cesión que tenía que hacer el Colegio de San Telmo de 30.000 pesos por orden del Consejo. s.a. Real Academia de la Historia, 9/1159, fols. 248-250

Sobre la fundación de un seminario de niños huérfanos para la marinería de las Armadas. 1681. Archivo Histórico Nacional, Consejos, leg. 13.215

Sobre las ventajas de los Colegios de San Telmo y el perjuicio de su falta. José Váz quez Figueroa. 1817, 5 marzo. Archivo Museo Naval, mss. 0435, doc. 5, fols. 262-263
Sobre los Colegios de San Telmo de Sevilla y Málaga. Habían llegado "al estremo mas deplorable [de] miseria y ruinosa situación". Fdo. José Vázquez Figueroa, secretario del despacho de Estado, que pide soluciones para acabar con esta situación. 1816, 23 julio. Archivo Museo Naval, mss. 0432, doc. 2, fols. 122-123

Sobre que se "recojan los planos de la obra del colegio de Sevilla y se satisfaga un valor al mro Ant ${ }^{\circ}$ Camargo q los hizo; y que si este no quisiere ponerlos en claro, se busque sujeto q lo execute". Antonio Camargo se negó a entregar los planos al contador don Francisco de Tuero, concuñado de Francisco Pizarro, "porque sabia ocultaba particulares fines". 1780. Archivo General de Simancas, Secretaría de Marina, leg. 216

Sobre que se declare exento al colegio de San Telmo del impuesto de 8 maravedíes en libra de carne. 1796. Archivo Histórico Nacional, Consejos, leg. 1.732

Sobre un incidente con un soldado que estaba de guardia en el Colegio de San Telmo. 1802. Archivo General de Palacio, Administraciones Patrimoniales, Reales Alcázares de Sevilla, caja 65, exp. 27

Solicitud del colegio de San Telmo de Sevilla, para que, para el mejor uso de su huerta, se mude una puerta que tiene el convento de San Diego. 1770. Archivo General de Simancas, Secretaría de Marina, leg. 215

ÁLVAREZ MIRANDA, V. Glorias de Sevilla. Sevilla. 1849

AMADOR DE LOS RíOS, J. Sevilla Pintoresca. Sevilla, 1844

ARANA DE VALFLORA, F. Compendio histórico y descriptivo de la ciudad de Sevilla. Sevilla, 1766

BARREDA, F. de. El arithmetico inferior, especulativo y práctico: dispuesto a la enseñanza de los colegiales del Real Seminario de San Telmo... Sevilla, 1770. Granada, Facultad de Teología de la Compañia de Jesús, A-B25f-1770

BARREDA, F. de. El marinero instruido en el arte de la navegación speculativo, y práctico, según el método, con que se enseña a los colegiales del Real Seminario del Sr. San Telmo, extra muros de la ciudad de Sevilla. Dispuesto por D. Francisco de Barreda, colegial, que fue en dicho Real Seminario...1766 (la licencia data de ese año). Reed. 1786. B.N.M., R/37273. Ed. posterior (ed. 1786, B.N.M., $1 / 204955$

GESTOSO Y PÉREZ, J. Sevilla monumental y artística. Historia y descripción de todos los edificios notables, religiosos y civiles que existen actualmente en esta ciudad y noticia de las preciosidades artísticas y arqueológicas que en ellos se conservan, Tomo III. Sevilla, 1892

GONZÁLEZ DE LEÓN, F. Noticia artística de Sevilla. Sevilla, 1844

JIMÉNEZ PLACER, L. "Nota acerca del edificio y jardines del palacio de San Telmo y parque de Maria Luisa. Redactada con toda urgencia y remitida a Madrid al Sr. Alcalde el día 27 de noviembre de 1929". 1929, 27 noviembre. Archivo Museo Naval, mss. 1575

LIMÓN Y ESPINOSA, M. Breve descripción del sumptuoso edificio Real Colegio Seminario llamado San Telmo. Sevilla, 1738. Biblioteca General de la Universidad de Sevilla, A. Mont. 04/6/05

LLAGUNO Y AMIROLA, E. Noticias de los arquitectos y arquitectura de España. Madrid, 1829

MAGÁN, N. V. Historia del Palacio de San Telmo. 1851, 18 septiembre. Archivo General del Arzobispado de Sevilla, leg. 730, núm. 2 (Colección del duque de Segorbe), según FALCÓN, T. El Palacio... 


\section{$064-065$}

\section{Criterios}

El Real Colegio Seminario

de San Telmo de Sevilla

$(1700-1780)$

\section{PH51 - Diciembre 2004}

MONTPENSIER, Casa de. Catálogo de los cuadros y esculturas pertenecientes a la galería de SS.AA.RR. Los Serenísimos Infantes de España, duques de Montpensier. Sevilla, 1866-1867. B.N.M., R/8454; Real Biblioteca, VIII/6496; Real Academia de Bellas Artes de San Fernando, LF-II/D-h/5023 (1)

MONTPENSIER, Casa de. Suplemento al catálogo de los cuadros y esculturas, con inclusión de las variaciones que han tenido en su colocación y números del catálogo [de la galería de los duques de Montpensier en el palacio de San Telmo]. Real Academia de Bellas Artes de San Fernando, 1867; B.N.M., R/8454

PONZ, A. Viaje de España. Madrid, 1780

SÁNCHEZ RECIENTE, J. Tratado de artillería theorica y practica en donde se da entera noticia y conocimiento de todas las piezas antiguas y juntamente de las modernas de la Nueva Ordenanza del año de 1716: según el methodo que se enseña en el Real Seminario de San Telmo, extramuros de la ciudad de Sevilla. Sevilla, 1733. Segovia, Academia de Artillería

SÁNCHEZ RECIENTE, J. Tratado de trigonometría náutica: y de la construcción, y uso de las escalas plana, y artificial, y de la tabla de partes meridionales, y algu nos problemas curiosos, que para la educación de los colegiales del Real Seminario del Señor San Telmo extramuros de la ciudad de Sevilla, disponele Don Juan Sánchez Reciente. Sevilla, 1742. Archivo Museo Naval, CF-484 (2)

SÁNCHEZ RECIENTE, J. Tratado de trigonometría náutica: y de la construcción, y uso de las escalas plana, y artificial, y de la tabla de partes meridionales, y algunos problemas curiosos, que para la educación de los colegiales del Real Seminario del Señor San Telmo extramuros de la ciudad de Sevilla, disponele Don Juan Sánchez Reciente. Madrid, 1759. Archivo Museo Naval, 15106 (2)

SERRANO ORTEGA, M. Noticia histórica del Seminario de Mareantes y Real Colegio de San Telmo de Sevilla. Sevilla, 1901. B.N.M., VC/91/27

BABIO WALLS, M. El Real Colegio Seminario de San Telmo: 1681-1981: bosquejo de su fundación. Sevilla, 198

BARRAS DE ARAGÓN, F. de la. Circunstancias que motivaron la fundación del Colegio de San Telmo de Sevilla. Madrid, 1935

BONET CORREA, A. Andalucia Barroca. Barcelona, 1978

BORREGO PLA, M. C. "Extracción social de los alumnos del Colegio de San Telmo de Sevilla", Actas de las I Jornadas de Andalucía y América. Sevilla, 1981

C.E.A. "El palacio de San Telmo en Sevilla". Arquitectura, núm. 119, 1929

CARREÑO PÉREZ, J. A. "Notas sobre la financiación del Real Colegio Seminario de San Telmo de Sevilla (1779-1783)" en Proyección histórica de España en sus tres culturas: Castilla y León, América y el Mediterráneo. Valladolid, 1993

CASTIllo MANRUBiA, P. "Los Colegios de San Telmo". Revista de Historia Naval núm. 13, 1986

DELGADO Y ORELLANA, J. A. "Catálogo de pruebas de nobleza del Real Colegio de San Telmo de Sevilla”. Hidalguía, 1985

FALCÓn MÁRQUEZ, T. El Palacio de San Telmo. Sevilla, Gever, 1991

FALCÓN MÁRQUEZ, T. "Jesucristo como modelo en el programa iconográfico de Palacio de San Telmo de Sevilla". Cuadernos de Arte e Iconografía, núm. 7, 1991
FERNÁNDEZ ALBÉNDIZ, M. C. La corte sevillana de los Montpensier. Sevilla, 1997

GÓmEZ DE TERREROS, A. "De la Torre de Don Fadrique y del Palacio de San Telmo (Sevilla)". Butlleti de la Reial Academia Catalana de Belles Arts Sant Jordi, núm. 9, 1995

HERRERA GARCÍA, A. "El colegio de San Telmo de Sevilla, Escuela de Mareantes para Indias. Addenda histórico-bibliográfica" en Comunicaciones presentadas al XI Congreso de Profesores-Investigadores. Palos de la Frontera, Huelva, 1992

HERRERA GARCÍA, A. "Estudio histórico sobre el Real Colegio Seminario de San Telmo de Sevilla". Archivo Hispalense, 1958

JIMÉNEZ JIMÉNEZ, E. M. "Desarrollo económico del Real Colegio de San Telmo de Sevilla en sus primeros años de funcionamiento (1681-1697)". Temas americanistas, núm. 14, 1998

JIMÉNEZ JIMÉNEZ, E. M. “La financiación del Real Colegio de San Telmo de SeviIla y su dependencia del tráfico comercial español con América (1698-1774)" en La economía marítima del Atlántico: pesca, navegación y comercio. Zaragoza, 1998

JIMÉNEZ JIMÉNEZ, E. M. "La contribución del derecho de toneladas de la Real compañía guipuzcoana de Caracas al Real Colegio de San Telmo de Sevilla (17301778)" en Comerciantes, mineros y nautas. Los vascos en la economía americana. Vitoria, 1996

JIMÉNEZ JIMÉNEZ, E. M. El Real Colegio Seminario de San Telmo de Sevilla (16811808): su contribución al tráfico marítimo con América y su significado en la historia de la ciudad en el siglo XVIII. Sevilla, 2002

JOS LÓPEZ, M. "La capilla de San Telmo". Arte Hispalense, núm. 43, 1986

LLEÓ CAÑAL, V. La Sevilla de los Montpensier: segunda corte de España. Sevilla, 1997

MANRUBIA CASTILLO, P. "Los colegios de San Telmo". Revista de Historia Naval, núm. 13, 1986

MENA GARCÍA, M. C. "La enseñanza en el Colegio de San Telmo a través de las ordenanzas de 1786". Archivo Hispalense, núm. 185, 1977

MENA GARCIAA, M. C. "Las propiedades del colegio seminario de San Telmo en el siglo XVII", en Andalucía y América en el siglo XVII, vol. I. Sevilla, 1985

MOLINO GARCÍA, M. T. "Admisión de alumnos en el Real Colegio Seminario de San Telmo de Sevilla". Temas americanistas, núm. 14, 1998

RIBELOT, A. Vida azarosa del Palacio de San Telmo: su historia y administración eclesiástica. Sevilla, 2001

RUIZ RIVERA, J. B. "Los precios del pan y de la carne en la contabilidad del Cole gio de San Telmo, Sevilla, 1760-1799”. Archivo Hispalense, núm. 184, 1977

SANCHO CORBACHO, A. Arquitectura sevillana del siglo XVIII. Madrid, 1952

SERRANO Y ORTEGA, M. Noticia histórica del Seminario de mareantes y Real Colegio de San Telmo de Sevilla. Sevilla, 1901

váZQUEZ CONSUEGRA, G. "Palacio de San Telmo". Aparejadores, núm. 11, 1983

VÁZQUEZ CONSUEGRA, G. Sevilla 100 edificios. Sevilla, 1986

VÁZQUEZ SOTO, J. M. San Telmo: biografía de un Palacio. Sevilla, 1990 